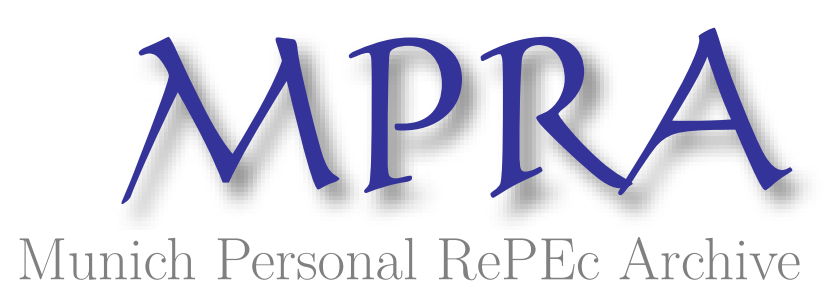

\title{
Interrelations among cross-currency basis swap spreads: Pre-and post-crisis analysis
}

Ibhagui, Oyakhilome

23 August 2018

Online at https://mpra.ub.uni-muenchen.de/89024/

MPRA Paper No. 89024, posted 17 Sep 2018 08:51 UTC 


\title{
Interrelations among cross-currency basis swap spreads: Pre-and post-crisis analysis
}

\begin{abstract}
We examine the long-run relationships and short-run dynamic linkages among 9 major cross-currency swap spreads, emphasizing how crisis periods have impacted long-run relationships and short-run dynamics. Results show that the long-run relationships were slightly weakened after crisis, while the short-run linkages were generally strengthened. The influence of euro and swiss cross-currency swaps on other European cross-currency swaps generally increased after crisis; the swiss cross-currency swap became much more influential on all European cross-currency swaps. Our findings are robust to alternative reordering of variables in our 9-variable VAR system, computation of generalized impulse response functions and consideration of rolling variance decompositions.
\end{abstract}

Keywords: Cross-currency basis swap spreads, Swap markets, Pre-and-post crisis

JEL Classification: C32, D53, F31, G01

\section{Introduction}

This paper empirically examines the long-run relationship and short-run dynamic linkages among an extended number of five-year Libor cross-currency basis swap spreads for major currencies - European currencies: euro (EUR/USD), Swedish krona (SEK/USD), British sterling (GBP/USD), Danish krone (DKK/USD) and Swiss franc (CHF/USD), and four other major currencies: Japanese yen (JPY/USD), Singaporean dollar (SGD/USD), New Zealand dollar (NZD/USD) and Canadian dollar (CAD/USD). We emphasize how past market crisis - particularly the global financial crisis and the eurozone sovereign crisis - has impacted the long-run relationship and short-run dynamic linkages among the cross-currency basis swap spreads. Most existing studies have focused on the magnitude or drivers of individual cross-currency basis swap spreads in crisis and tranquil periods. Instead, this paper focuses on the links among a collection of major cross-currency basis swap spreads and compares their interrelations in the pre-crisis and post-crisis periods to determine whether and how the crisis has influenced the links.

As a brief exposition, a cross-currency basis swap allows two parties - which could be large corporates, investment firms, financial institutions or even governments - to borrow from and concurrently lend to each other the same amount of money denominated in two different currencies at the spot exchange rates for a predefined maturity. At the start of and throughout the life of the swap, the two parties exchange nominals denominated in two different currencies, equivalent in value at the spot exchange rate, and floating interest rate payments, typically quarterly as the interest expense or interest income for the nominal amount borrowed or lent. At maturity, the same nominals are re-exchanged at the forward exchange rate pre-determined at the time of entering the swap transaction. Thus, the future spot exchange 
rate does not influence the nominals at maturity. This is the reason that cross-currency basis swaps are mostly FX riskfree. One of the major players in the swap markets are financial institutions which mainly use swaps for hedging purposes or to meet their foreign currency funding needs. The spread on the cross-currency basis swap is either negative or positive. It is negative if the currency is perceived as riskier than the USD, otherwise it is positive. The spread is usually quoted on the non-USD Libor leg; the more negative is the spread, the higher the demand for USD liquidity because of market perception of a higher risk in the pair currency. The same is true when a positive basis spread becomes less positive. The opposite holds if a negative spread becomes less negative or a positive spread becomes more positive.

According to Du et.al (2018), the foreign exchange forward and swap market is among the largest and most liquid derivative markets in the world with a total notional amount outstanding of more than $\$ 50$ trillion. Since the emergence and development of cross-currency swap markets, the linkages of cross-currency basis swap spreads across different swap markets have surprisingly not been given much attention in the empirical finance literature. Studies examining the potential drivers of a wide array of cross-currency basis swap spreads are increasingly more popular in the international finance literature, not least because the basis has deviated significantly from covered interest rate parity and, in most cases, remains significantly different from zero even in periods characterized by tranquility, lower funding pressure and mitigated risks. However, an equally important topic concerning the linkages among cross-currency swap markets has received little or no attention. Existing research has traditionally focused on deviations of cross-currency basis swaps from covered interest rate parity (see Popper (1993), Takezawa (1995) and Baba et al. (2008)), and drivers of crosscurrency basis (see Du et al. (2018)).

In one of the first few attempts to empirically investigate linkages among cross-currency swaps, Tamakoshi and Hamori (2013) examine the impact of the European sovereign crisis on the linkages among three European cross-currency swaps - EUR/USD, CHF/USD and GBP/USD. Their results suggest that the links among the swaps are generally higher during the crisis period, suggesting more market connectedness during the crisis. However, the influence of a crisis on the short- and long-run linkages of the cross-currency swaps remains unknown. For instance, the linkages among crosscurrency swaps prior to the crisis, and whether the nature of these linkages has since metamorphosed after the crisis, are two important questions which are yet to be addressed in the literature. Furthermore, the short-and long-run linkages in the pre-crisis and post-crisis periods among an extended number of cross-currency swaps, beyond European swaps, remain unclear in the finance literature. These are germane questions, with relevance in academia and to practitioners, which the extant literature is yet to formally address. This paper attempts to fill this void.

In this paper, the extent and nature of analysis of the cross-currency swap market linkages cover both long-run relationship and short-run dynamic linkages, where the former is most relevant for exploiting the long-run gains from international diversification in a portfolio of cross-currency swaps, while the latter sheds light on the network links or propagation mechanisms of fluctuations in international cross-currency markets. Meanwhile, the 2007-2012 global 
financial and eurozone sovereign crisis popularized the basis spread. However, it remains unexplored and unknown how this crisis period alters the linkages among cross-currency markets. This paper addresses this void in the literature. Our contribution to the literature is twofold. First, we separate our analysis into the pre-crisis and post-crisis periods and analyze the long-run relationships and short-run dynamic linkages among the cross-currency swaps in these periods. After confirming the existence of one cointegrating relationship in both the pre-crisis and post-crisis periods, we use the vector error correction model, together with the persistence profile technique and speed of adjustment analysis, to examine the impact of the crisis on the long-run relationships. This enables us to analyze not only the long-run equilibrium relationships, but also to estimate the speed of convergence to the long-run equilibrium following a systemwide shock or deviation from equilibrium. According to Yang et al. (2006), the persistence profile technique reveals the true evolution of long-run relationships and speed of convergence, which are otherwise undiscovered and difficult to detect when long-run inferences are based on examining the number of cointegrating vectors alone. In the short run analysis, we investigate the intra-regional linkages within the European swap markets and inter-regional linkages between European swaps and other swaps considered in this paper. As before, we perform this analysis for the pre-crisis and post-crisis periods.

Our general findings are that although the long-run relationships among the cross-currency swaps were slightly weakened after the crisis, the short-run dynamic linkages were generally strengthened after the crisis. In particular, the influence of EUR/USD cross-currency swap on other European cross-currency swaps generally increased after the crisis and, interestingly, the influence of CHF/USD cross-currency swap became much more noticeable on all other European cross-currency swaps only after the crisis, but not before the crisis. We conduct several robustness checks to gauge the sensitivity of our results to changes in assumptions. Our overall findings continue to stand and are robust to alternative reordering of the variables, computation of generalized impulse response functions and consideration of rolling variance decompositions.

The rest of this paper is organized as follows. Section 2 describes the data used in this study. Section 3 outlines the empirical design. In Section 4, we present the estimation results and empirical findings. Section 5 presents the implications of our main findings for investment management, while Section 6 concludes the paper with pointers for potential future research work.

\section{Data}

To investigate cross-currency swap linkages, our analysis requires the use of data on cross-currency basis swap spreads associated with the nine currencies in our sample. The cross-currency basis swap spreads data, provided by Bloomberg, consist of different countries' basis swaps with respect to the US dollar, where the convention adopted is one in which the basis is added to the non-dollar leg of the swap. For all the swap markets represented on Bloomberg, the earliest date 
for which data samples are available is early 2000s. We use Libor-based, 5-year cross-currency basis swap spreads as this was the portion of the swap curve for which data samples were most available for all countries considered. Our data consist of daily cross-currency basis swap spreads closing levels of Japanese yen (JPY/USD), Singaporean dollar (SGD/USD), New Zealand dollar (NZD/USD), Canadian dollar (CAD/USD), and five European swaps - euro (EUR/USD), Swedish krona (SEK/USD), British sterling (GBP/USD), Danish krone (DKK/USD) and Swiss franc (CHF/USD). The sample period is from February 1, 2002 to May 31, 2018, which includes 4259 daily observations for each series.

\section{Table 1: Definitions of variables}

\begin{tabular}{ll}
\hline Variables & Definition of variables \\
\hline$(\mathbf{C A D} / \mathbf{U S D})_{\mathbf{t}}$ & 5-year Canadian Dollar/US Dollar cross-currency basis swap spread \\
$(\mathbf{C H F} / \mathbf{U S D})_{\mathbf{t}}$ & 5-year Swiss Franc/US Dollar cross-currency basis swap spread \\
$(\mathbf{D K K} / \mathbf{U S D})_{\mathbf{t}}$ & 5-year Danish Krone/US Dollar cross-currency basis swap spread \\
$(\mathbf{E U R} / \mathbf{U S D})_{\mathbf{t}}$ & 5-year Euro/US Dollar cross-currency basis swap spread \\
$(\mathbf{G B P} / \mathbf{U S D})_{\mathbf{t}}$ & 5-year British Pound Sterling/US Dollar cross-currency basis swap spread \\
$(\mathbf{J P Y} / \mathbf{U S D})_{\mathbf{t}}$ & 5-year Japanese Yen/US Dollar cross-currency basis swap spread \\
$(\mathbf{N Z D / U S D})_{\mathbf{t}}$ & 5-year New Zealand Dollar/US Dollar cross-currency basis swap spread \\
$(\mathbf{S E K} / \mathbf{U S D})_{\mathbf{t}}$ & 5-year Swedish Krona/US Dollar cross-currency basis swap spread \\
$(\mathbf{S G D} / \mathbf{U S D})_{\mathbf{t}}$ & 5-year Singapore Dollar/US Dollar cross-currency basis swap spread
\end{tabular}

Note: CAD, CHF, DKK, EUR, GBP, JPY, NZD, SEK and SGD represent Canadian dollar, Swiss franc, Danish krone, Euro, British pound sterling, Japanese yen, New Zealand dollar, Swedish krona and Singaporean dollar respectively while USD represents US dollar.

In line with the objective of this paper, the sample period is divided into the before and after crisis periods to address the potential impact of the 2007-2012 global financial crisis and European sovereign crisis on the intra-and inter-linkages of the cross-currency swap markets. According to the US Fed (2013), the global financial crisis began in December 2007 and ended in June 2009, while it is well documented that the European sovereign debt crisis started shortly after the global financial crisis and lasted until around July 2012. Consequently, in this study, we divide the sample observations into two non-overlapping sub-periods: before crisis period, from February 2002 to November 2007, and after crisis period from August 2012 to May 2018. This provides a platform that allows for possible transitory periods of moving to and exiting from the crisis. Our analysis focuses on the before and after crisis periods because the effect that the crisis has had on swap market linkages in the short-run and long-run possibly becomes more visible when the pre-crisis and post-crisis periods are compared. 


\section{Empirical design}

Let $X C C Y_{t}$ be a vector of $n=9$ non-stationary cross-currency basis swap spreads. These are the nine cross-currency swaps to be analyzed in this paper. They can be appropriately modelled in a vector error correction model (VECM), with $p-1$ lags as follows

$$
\Delta X C C Y_{t}=\Lambda X C C Y_{t-1}+\sum_{i=1}^{p-1} \psi_{i} \Delta X C C Y_{t-1}+\mu+\varepsilon_{t}
$$

where $t=1, \ldots, T, \Delta$ is the usual first difference operator $\left(\triangle X C C Y_{t}=X C C Y_{t}-X C C Y_{t-1}\right), X C C Y_{t}$ is a $(9 \times 1)$ vector of cross-currency basis swap spreads, $\Lambda$ is a $(9 \times 9)$ matrix of coefficients such that $\Lambda=\alpha \beta^{\prime}, \psi_{i}$ is a $(9 \times 9)$ matrix of short-run dynamic coefficients, and $\varepsilon_{t} \sim i i d\left(0, \sum\right)$ is a $(9 \times 1)$ vector of innovations. $\wedge$ contains information about the long-run cointegrating relations among the $n=9$ cross-currency basis swap spreads. In general, there are three possible cases: i) if $\Lambda$ is of full rank such that the number of cointegrating relations equals the number of variables in the system, i.e. $r=n=9$ ranks, then each variable in $X C C Y_{t}$ is necessarily stationary at levels, and an appropriate modelling strategy is the VAR in levels; ii) if the rank of $\Lambda$ is zero, then it contains no long-run information, and the appropriate modelling strategy is a VAR in first difference; iii) lastly, if the rank of $\Lambda$ is some $r \in \mathbb{Z}^{+} \mid r<n=9$, then $\exists$ matrices $\alpha$ and $\beta$, with dimension $n \times r$, such that $\Lambda=\alpha \beta^{\prime}$, and $\beta^{\prime} X C C Y_{t}$ is stationary even when $X C C Y_{t}$ is nonstationary.

As will be seen in the subsequent section of this paper, case (iii) holds since all $X C C Y_{t}$ generally enter the model as nonstationary variables and Johansen trace test shows there is one cointegration rank. Meanwhile, the parameters on the above VECM can be used to generate information on the required long-run relationship and short-run dynamics. By way of context, the long-run relationship can be identified through a test of hypotheses on $\beta$, whereas the short-run dynamics can be identified by testing hypotheses on $\alpha$ and $\psi$. The long-run cointegration analysis in this study employs the Johansen trace test alongside the persistence profile technique a la Pesaran and Shin (1996) and speed of adjustment contained in the VECM system. Using the VECM when variables are both I(1) and cointegrated produces more efficient estimators of the cointegrating vectors because the VECM is a full information maximum likelihood (ML) estimation model. One major advantage of the VECM is that it provides an optimal framework for examining cointegration relationships in a high-dimensional system of equations in one step, and does not require the more time-consuming equation-by-equation analysis of cointegration where a specific variable needs to be normalized for each equation.

The dynamic interactions among the cross-currency swaps are also summarized in the above model. The innovations from the VAR/VECM system are unexpected changes in each cross-currency swap that cannot be predicted by information contained in the observed cross-currency swaps or those from other swap markets. The lagged transmission mechanism of each cross-currency swap - based on its observed movement - is captured by the coefficients on the lagged explanatory variables in each of the 9 equations of the VAR model. In other words, the influence of a swap A at 
time, say, $t-1$ on another swap B at time $t$ is captured by the coefficients on the lagged changes in swap A in the equation explaining the changes in swap B. In this context, the forecast error variance decomposition allows for such dynamics of information transmission, and measures how much of the movements in one cross-currency swap can be explained by innovations in the other cross-currency swaps in the system. The vector error correction model would be estimated to investigate the long run relationships and summarize short-run dynamic influence that each swap market has on other swap markets. To achieve the latter, forecast error variance decomposition is conducted to summarize the dynamic interactions among the 9 cross-currency basis swap spreads. The forecast error variance decomposition provides a direct examination of linkages among variables in the short-run dynamic sense.

In this study, rather than comparing the number of ranks or cointegrating vectors in the pre-crisis and post-crisis era to examine the strength of long-run relations, we draw intuition from the persistence profile technique of Pesaran and Shin (1996) which allows us to estimate the speed of convergence to equilibrium following a shock to the system. As Yang (2006) notes, the strength of long-run relationships does not necessarily correspond to the number of co-integrating vectors. Instead, it is a function of how fast a system returns to equilibrium following a deviation due to shocks to the system. Examining the speed of convergence provides insights into the proportion of disequilibrium corrected or the amount of equilibrium achieved on a given date. It indicates how soon it takes a system to return to the long-run equilibrium relationship once shocked. A higher speed of adjustment to equilibrium indicates a stronger long-run relationship. In our context, it can help to reveal whether the long-run relationship among the cross-currency swaps have become stronger or weaker after the crisis, thus revealing if the cross-currency swap spreads have become either more or less integrated after the crisis.

\section{Empirical results}

\subsection{Long-run cointegration relations and VECM estimation}

As is standard in the literature, cointegration requires all variables to be integrated of the same order I(1), so we first investigate the order of integration by performing unit root tests before proceeding to testing whether the swap series are co-integrated. Four standard procedures, the augmented Dickey-Fuller (ADF) test, Phillips-Perron (PP) test, ADFGLS test and KPSS test, are applied to check the non-stationarity/stationarity of each series, with a decision rule that a series is non-stationary if at least one test yields a non-stationary series. The comprehensive unit root test results (not reported but readily available on request) show that most of the tests cannot reject the null hypothesis of non-stationarity for most of the series both in the pre-crisis and post-crisis periods. All the variables in first differences are normally stationary at the $5 \%$ significance level or better. Thus, there exists a unit root in each cross-currency basis swap spreads in both the before and after crisis periods, but no unit root in their first difference at the $5 \%$ level of significance. Having I(1) variables sets the stage for the Johansen test for cointegration. As such, the vector of cross-currency basis swap 
spreads to be examined is given by $X C C Y_{t}=\left[(E U R / U S D)_{t},(S E K / U S D)_{t},(C H F / U S D)_{t},(D K K / U S D)_{t},(G B P /\right.$ $\left.U S D)_{t},(C A D / U S D)_{t},(N Z D / U S D)_{t},(J P Y / U S D)_{t},(S G D / U S D)_{t}\right]$

Next, we select the optimal lag for the system of equations in (1). For the pre-crisis and post-crisis periods, 8 and 7 lags are chosen respectively. At these lags, diagnostic tests show that there is no problem of serial correlation in the residuals. For the pre-crisis and post-crisis periods, the Lagrange multiplier test yields p-values of 0.14 and 0.08 respectively, failing to reject the null hypothesis of no residual correlation at the 5\% level in both periods. Thus, we apply these lags in the Johansen cointegration test.

Moving to the test for cointegration, Table 2 reports the results and critical values of the Johansen cointegration test. The trace test indicates that there is one cointegrating relation in the pre- and post-crisis periods, allowing us to conclude that there is one cointegrating vector.

Table 2: Johansen trace test

\begin{tabular}{|c|c|c|c|c|c|c|c|}
\hline \multicolumn{4}{|c|}{ Before Crisis } & & \multicolumn{3}{|c|}{ After Crisis } \\
\hline No. of CE(s) & Trace Statistic & $5 \%$ Critical Value & Prob. & No. of $\mathrm{CE}(\mathrm{s})$ & Trace Statistic & 5\% Critical Value & Prob \\
\hline None $*$ & 209.841 & 197.371 & 0.010 & None * & 211.780 & 197.371 & 0.008 \\
\hline At most 1 & 156.657 & 159.530 & 0.071 & At most 1 & 158.884 & 159.530 & 0.054 \\
\hline At most 2 & 104.682 & 125.615 & 0.453 & At most 2 & 108.541 & 125.615 & 0.339 \\
\hline At most 3 & 77.980 & 754 & 0.435 & At most 3 & 76.430 & 95.754 & 0.491 \\
\hline At most 4 & 53.715 & 69.819 & 0.474 & At most 4 & 47.765 & 69.819 & 0.731 \\
\hline At most 5 & 30.384 & 47.856 & 0.699 & At most 5 & 27.240 & 47.856 & 0.845 \\
\hline At most 6 & 15.909 & 29.797 & 0.719 & At most 6 & 15.263 & 29.797 & 0.763 \\
\hline At most 7 & 6.281 & 15.495 & 0.662 & At most 7 & 7.579 & 15.495 & 0.512 \\
\hline At most 8 & 0.959 & 3.841 & 0.327 & At most 8 & 1.686 & 3.841 & 0.194 \\
\hline
\end{tabular}

Note: No. of CE(s) is the rank or number of cointegrating vectors in each period; * means reject the hypothesis at the 5\% level. Where * does not appear, it means the null hypothesis cannot be rejected at the 5\% level. Trace test indicates 1 cointegrating equation at the 5\% level for both the pre-crisis and post-crisis period. Thus, we have a single cointegration rank for each period.

The Johansen trace test results are reported in Table 2. For both periods, the test indicates the existence of one cointegrating vector in both the before crisis and after crisis periods at 5\% level since the null hypothesis at this cointegration rank cannot be rejected at the stated level of significance. Thus, there is one rank or cointegrating relationship among the cross-currency basis swap spreads both in the pre-crisis and post-crisis periods. We next present the estimated cointegrating vectors based on VECM for both periods.

Our estimated co-integrating vector for the after-crisis period, based on the vector error correction model normalized on $E U R / U S D, \quad$ is $\quad \beta=(1.000,0.961,-1.838,-0.423,1.065,-1.739,-0.223,0.219,1.251,0.69)$, yielding the following cointegrating relationship 


$$
\begin{aligned}
(E U R / U S D)_{t}= & -0.961\left(\frac{S E K}{U S D}\right)_{t}+1.838\left(\frac{C H F}{U S D}\right)_{t}+0.423\left(\frac{D K K}{U S D}\right)_{t}-1.065\left(\frac{G B P}{U S D}\right)_{t}+1.739\left(\frac{C A D}{U S D}\right)_{t} \\
& +0.223\left(\frac{N Z D}{U S D}\right)_{t}-0.219\left(\frac{J P Y}{U S D}\right)_{t}-1.251\left(\frac{S G D}{U S D}\right)_{t}-0.698
\end{aligned}
$$

In this long-run relation, $(E U R / U S D)_{t}$ is negatively related to $(S E K / U S D)_{t},(G B P / U S D)_{t},(J P Y / U S D)_{t}$ and $(S G D / U S D)_{t}$ cross-currency swaps while it bears positive relations with $(C H F / U S D)_{t},(D K K / U S D)_{t},(C A D / U S D)_{t}$, and $(N Z D / U S D)_{t}$ cross-currency swaps. This implies that when $(C H F / U S D)_{t},(D K K / U S D)_{t},(C A D / U S D)_{t}$ or $(N Z D / U S D)_{t}$ cross-currency swap improves (that it, tightens/becomes less negative or improves/becomes more positive) in the long-run, the $(E U R / U S D)_{t}$ will also improve, lowering the cost of synthetic USD as it becomes relatively cheaper to access USD by issuing a paper in EUR and swapping the proceeds to USD in the EUR/USD swap market. An improvement in these swaps is particularly a welcome development for those seeking synthetic USD via the EUR/USD as it leads to a tightening of the $(E U R / U S D)_{t}$ basis and a fall in the associated cost of accessing synthetic USD in the EUR/USD cross-currency markets. Thus, factors that will cause $(C H F / U S D)_{t},(D K K / U S D)_{t},(C A D /$ $U S D)_{t}$ or $(N Z D / U S D)_{t}$ to improve in the long run are also positive for the $(E U R / U S D)_{t}$ basis. On the other hand, when $(G B P / U S D)_{t},(S E K / U S D),(J P Y / U S D)_{t}$ or $(S G D / U S D)_{t}$ cross-currency swaps improve in the long-run, the $(E U R / U S D)_{t}$ cross-currency basis will worsen. That is, $(E U R / U S D)_{t}$ cross-currency basis spread will widen by more than a basis point when either $(G B P / U S D)_{t}$ or $(S G D / U S D)_{t}$ improves by one basis point. Thus, improvement in these cross-currency swaps results in a widening of the $(E U R / U S D)_{t}$ cross-currency basis in the long-run, which is bad news for institutions looking to generate synthetic USD via issuing in EUR and swapping into USD in the EUR/USD swap market as such transaction becomes relatively more expensive.

The findings in the post-crisis period seem to suggest that the $(E U R / U S D)_{t}$ swap in the long-run responds quite differently even to movements in swaps domiciled in the same region. In line with exclusion restrictions, we check whether certain cross-currency swap spreads can be excluded from the co-integrating vector in the post-crisis period. We find that none of the European swaps can be individually excluded from the long-run relationship at the $10 \%$ level. However, two of the European swaps, $(S E K / U S D)_{t}$ and $(D K K / U S D)_{t}$, can be individually excluded from the long-run relationship, at the 5\% significance level, and it appears that the NZD/USD and JPY/USD swaps can be excluded in the after-crisis period at the $10 \%$ level. Overall, the restriction of excluding all European markets in the post-crisis period is firmly rejected at $5 \%$ or better.

In the pre-crisis period, the estimated co-integrating vector is $\beta=$ $(1.000,0.986,0.388,0.409,-0.789,0.069,0.097,-0.182,-0.212,-10.591)$, giving rise to the following cointegrating relationship 


$$
\begin{aligned}
(E U R / U S D)_{t}= & -0.986\left(\frac{S E K}{U S D}\right)_{t}-0.388\left(\frac{C H F}{U S D}\right)_{t}-0.409\left(\frac{D K K}{U S D}\right)_{t}+0.789\left(\frac{G B P}{U S D}\right)_{t}-0.069\left(\frac{C A D}{U S D}\right)_{t} \\
& -0.097\left(\frac{N Z D}{U S D}\right)_{t}+0.182\left(\frac{J P Y}{U S D}\right)_{t}+0.212\left(\frac{S G D}{U S D}\right)_{t}+10.591
\end{aligned}
$$

Apart from $(S E K / U S D)_{t}$ which is negatively related to $(E U R / U S D)_{t}$ in the long-run both in the pre-crisis and postcrisis periods, it is interesting to note that the long-run relationship in the pre-crisis period is the direct opposite of the post-crisis relationship. Specifically, in the pre-crisis long-run relationship, an improvement in $(C H F / U S D)_{t}$, $(D K K / U S D)_{t},(C A D / U S D)_{t}$ or $(N Z D / U S D)_{t}$ worsens the $(E U R / U S D)_{t}$ cross-currency swap, whereas in the postcrisis period, it improves the $(E U R / U S D)_{t}$. Similarly, $(G B P / U S D)_{t},(J P Y / U S D)_{t}$ or $(S G D / U S D)_{t}$, which is positively related to the $(E U R / U S D)_{t}$ in the pre-crisis period worsens the $(E U R / U S D)_{t}$ in the post crisis period. Clearly, apart from the sign of the coefficient of $(S E K / U S D)_{t}$ which is robust in both periods and may allow us to infer that to a large extent, the $(E U R / U S D)_{t}$ has a negative long-term relation with $(S E K / U S D)_{t}$, at least at the $10 \%$ level, the crisis has since changed the vibe of the overall long-run relationship, and a long run strategy which worked prior to the crisis is unlikely to the effective post crisis. This leads us to believe that, by and large, the $(E U R / U S D)_{t}$ tends to follow directions taken by different cross-currency swaps in the post-crisis period compared to the ones followed in the pre-crisis period.

Turning now to the swaps which can be possibly excluded from the long-run relationship, we see that in contrast with the after-crisis period, only $(N Z D / U S D)_{t}$ can be excluded from the long-run relationship at the $10 \%$ significance level in the pre-crisis period and none of the European markets can be excluded at the $10 \%$ level; however, at the 5\% level, only CHF/USD cross-currency basis can be excluded among the European swaps, and CAD/USD swap for the other markets. As with the after-crisis period, the restriction of excluding all European swaps during the period is strongly rejected at any conventional significance level.

Overall, at the 5\% level, three individual swaps $\left((C H F / U S D)_{t},(C A D / U S D)_{t}\right.$ and $\left.(N Z D / U S D)_{t}\right)$ can be excluded from the cointegrating vector of the long-run relationship in the pre-crisis period. This increases to four individual swaps $\left((S E K / U S D)_{t},(D K K / U S D)_{t},(N Z D / U S D)_{t}\right.$ and $\left.(J P Y / U S D)_{t}\right)$ after the crisis period. Thus, the before and after crisis period analysis provides some evidence that the long-run relationships among the cross-currency swaps appears to be stronger in the pre-crisis period compared to after the crisis.

Meanwhile, the cointegrating vector for the before and after crisis periods, plotted in the graphs below, show that longrun cointegrating relationship indeed exists in the pre-crisis and post-crisis periods as the cointegration residuals in both periods are strongly stationary, suggesting that the estimated cointegrating vector is appropriate. The graphs also appear to suggest that restoration of the long-run cointegrating relationships after a system-wide shock tends to be faster in the pre-crisis period than after the crisis. As can be seen in the graphs, deviations are much larger in the post-crisis cointegration vector and thus would take a longer time to dissipate, lowering the speed of convergence to equilibrium. 
Figure 1: Graphical illustration of cointegration vector normalized with respect to (EUR/USD)

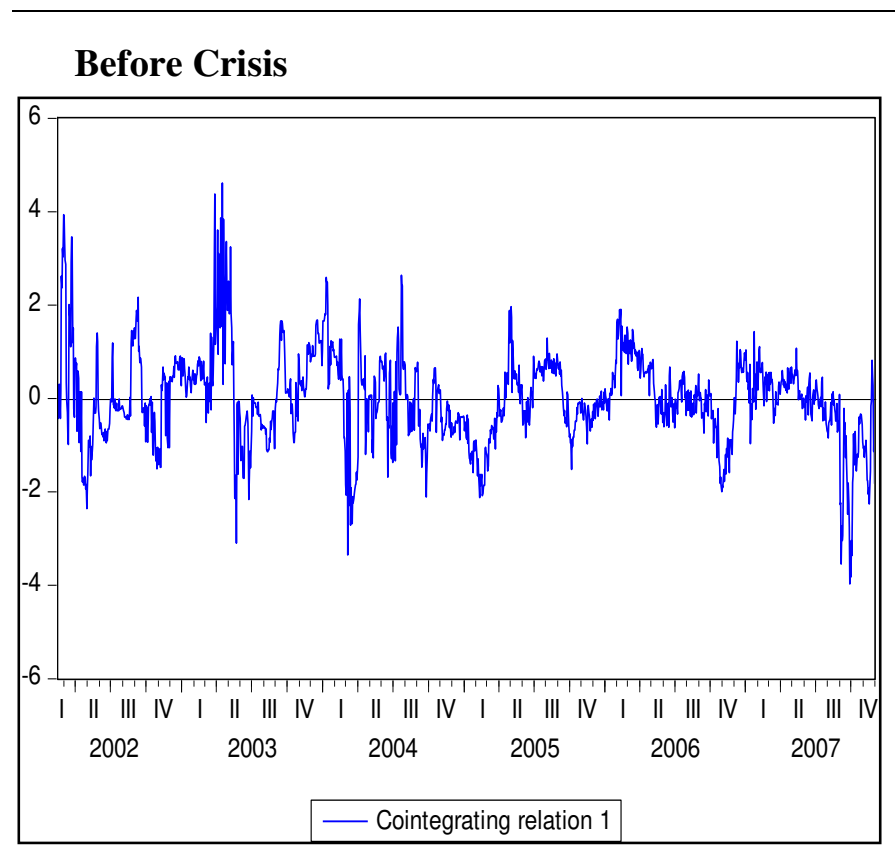

\section{After Crisis}

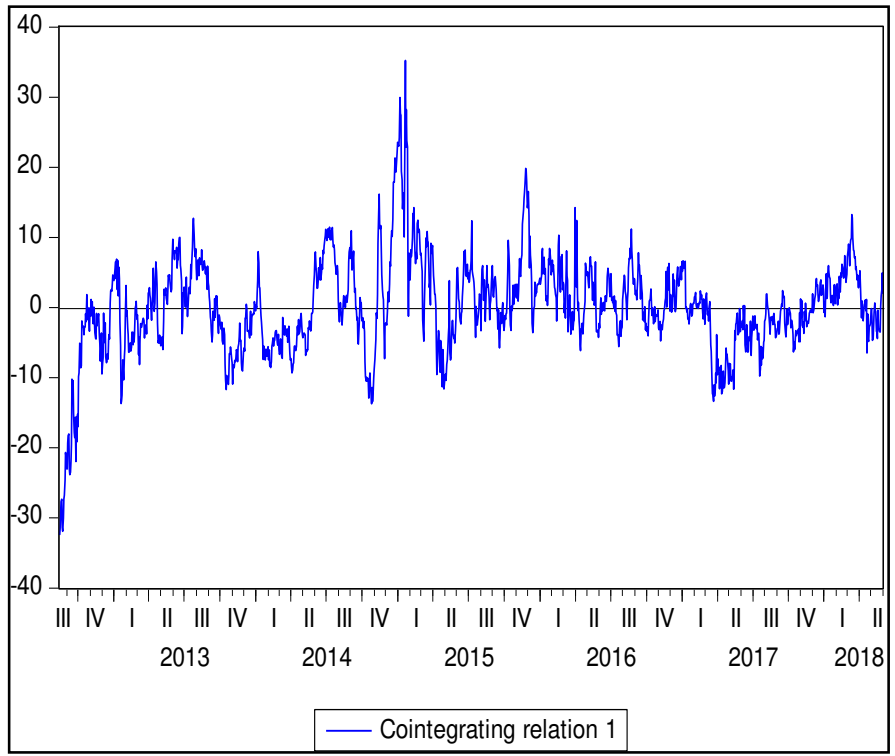

\subsection{Weak exogeneity of adjustment coefficients}

Below, we present the estimates of the error correction coefficients that govern the adjustment to the long run equilibrium. This would enable us to test for weak exogeneity as well as determine the speed of adjustment to long run equilibrium based on our VECM model.

Table 3: Error-correction coefficient estimates

\begin{tabular}{|c|c|c|c|c|c|c|c|c|c|}
\hline & $\begin{array}{l}(\boldsymbol{E U} \boldsymbol{R} \\
/ \boldsymbol{U S D})_{t}\end{array}$ & $\begin{array}{l}(\boldsymbol{S E K} \\
/ \boldsymbol{U S D})_{t}\end{array}$ & $\begin{array}{l}(\boldsymbol{C H F} \\
/ \boldsymbol{U S D})_{t}\end{array}$ & $\begin{array}{l}(D K K \\
/ U S D)_{t}\end{array}$ & $\begin{array}{l}(\boldsymbol{G B P} \\
/ \boldsymbol{U S D})_{t}\end{array}$ & $\begin{array}{l}(C A D \\
/ U S D)_{t}\end{array}$ & $\begin{array}{l}(N Z D \\
/ U S D)_{t}\end{array}$ & $\begin{array}{l}(J P Y \\
/ U S D)_{t}\end{array}$ & $\begin{array}{l}(S G D \\
/ U S D)_{t}\end{array}$ \\
\hline Before crisis & $\begin{array}{l}-0.019 * * \\
(-2.310)\end{array}$ & $\begin{array}{l}-0.031 * * * \\
(-3.235)\end{array}$ & $\begin{array}{l}-0.001 * \\
(-0.149)\end{array}$ & $\begin{array}{l}-0.001 * \\
(-0.117)\end{array}$ & $\begin{array}{l}0.037 * * * \\
(3.715)\end{array}$ & $\begin{array}{l}-0.003 * \\
(-0.242)\end{array}$ & $\begin{array}{l}0.002 * \\
(0.112)\end{array}$ & $\begin{array}{l}0.026 * * \\
(2.166)\end{array}$ & $\begin{array}{l}0.055^{* * *} \\
(3.429)\end{array}$ \\
\hline$R^{2}$ & 0.147 & 0.339 & 0.346 & 0.282 & 0.279 & 0.093 & 0.128 & 0.178 & 0.111 \\
\hline After crisis & $\begin{array}{l}-0.011 * * * \\
(-3.391)\end{array}$ & $\begin{array}{l}-0.004 * \\
(-1.657)\end{array}$ & $\begin{array}{l}0.007 * \\
(1.712)\end{array}$ & $\begin{array}{l}-0.003 * \\
(-0.625)\end{array}$ & $\begin{array}{l}-0.006 * * \\
(-2.441)\end{array}$ & $\begin{array}{l}0.007 * * * \\
(3.166)\end{array}$ & $\begin{array}{l}0.002 * \\
(0.743)\end{array}$ & $\begin{array}{l}-0.006 * \\
(-1.272)\end{array}$ & $\begin{array}{l}-0.011 * * * \\
(-3.466)\end{array}$ \\
\hline$R^{2}$ & 0.073 & 0.139 & 0.095 & 0.206 & 0.092 & 0.057 & 0.034 & 0.073 & 0.092 \\
\hline
\end{tabular}


To check for weak exogeneity of the adjustment coefficients, we examine the swaps that adjust to restore equilibrium and in so doing, we gain insight into how the long-run equilibrium is restored among the cross-currency swap spreads. We also estimate the multivariate vector error-correction model (VECM) and focus on the significance of the adjustment coefficients. Table 3 reports the estimates of the adjustment coefficients that govern the adjustment to the long-run equilibrium. For NZD/USD, CAD/USD, DKK/USD and CHF/USD cross-currency swaps, the estimated errorcorrection coefficients are not significant. This implies these swaps are weakly exogeneous, suggesting that the null hypothesis of a zero restriction on their adjustment coefficients cannot be rejected at the $5 \%$ level. In other words, when deviations from long-run equilibrium occurs in the pre-crisis period, it is primarily the other cross-currency swaps, not the weakly exogeneous ones, that adjust to ensure that long-run equilibrium is restored. Thus, these weakly exogeneous swaps can possibly be omitted from the interdependent system of endogenous variables - but not from the entire system of the long-run cointegrating vector - as they do not drive the adjustment process. In total, 4 cross-currency swaps are weakly exogeneous in the pre-crisis period, at the $5 \%$ level of significance. At most, the other five cross-currency swaps adjust to ensure that equilibrium is restored.

Turning now to the post-crisis period, we note that the number of weakly exogeneous cross-currency swaps, at the 5\% significant level, rises to five (i.e. five of the coefficients are small and insignificant). They are SEK/USD, CHF/USD, DKK/USD, NZD/USD and JPY/USD, implying that at most four of the other swaps, rather than the weakly exogenous ones, adjust to restore long-run equilibrium following system-wide shocks. On the whole, compared to the pre-crisis era, the weak exogeneity test indicates that there are more weakly exogenous swaps in the post crisis period at the 5\% level compared to the pre-crisis period. Further, the different magnitude of adjustment mechanisms at work in the two periods possibly reflect varying degrees of long-run linkages among the swap markets due to the crisis. Meanwhile, the instances with positive and significant coefficients point to the lack of a speedy built-in adjustment mechanism to the long-run equilibrium.

Among the European swap markets, CHF/USD and DKK/USD cross-currency swaps are each weakly exogeneous to the other cross-currency swaps both in the pre-crisis and post-crisis periods while JPY/USD became weakly exogeneous to the other markets during the post-crisis period. Interestingly, while CHF/USD cross-currency swaps cannot be excluded from the co-integrating vector in the post-crisis period, the DKK/USD cross-currency swap cannot be excluded from the cointegrating vector in the pre-crisis period. The combined evidence thus suggests that CHF/USD swap plays a more informative role in the post-crisis period than in the pre-crisis period while the reverse is possibly true for DKK/USD. NZD/USD is weakly exogenous in both periods, and the exclusion tests suggest that it can be excluded from the entire system of cointegrating vector.SEK/USD and JPY/USD cross-currency swaps are each weakly exogenous in the post-crisis period and can be excluded from the cointegrating vector in this period. 


\subsection{Persistence profile and convergence to equilibrium}

We now formally investigate whether the crisis period has influenced (quickened or slowed) the long-run relationships among the swaps. To do this, we follow Pesaran and Shin (1996) and examine the persistence profile of the cointegrating vectors in the pre-crisis and post-crisis periods. The persistence profile provides approximate time horizons required for cointegration relationships to return to equilibrium following a system-wide shock. In our application, it depicts the response of the cointegration system/long-run relationships to shocks over time and determines in which period (pre- or post-crisis) the long-run equilibrium is faster restored following a system-wide shock.

The persistence profile, reported in Fig. 2, suggests that the convergence to long-run equilibrium appears to be much faster prior to the crisis than in the post-crisis period. Specifically, as shown in Figure 2, after 100 days, the shocks to the cointegrating vector in the pre-crisis period have largely dissipated and approaching the equilibrium state, whereas the dissipation of shocks to the cointegrating vector in the post-crisis period is only roughly half-way after 100 days. In other words, after the same number of days, more of the shocks to equilibrium have dissipated, with the system much closer to equilibrium, in the pre-crisis period than in the post-crisis period. Taken together, this finding suggests that the cross-currency swaps exhibit a stronger, more cohesive long-run relationship in the pre-crisis period than in the postcrisis period. Their degree of integration is stronger as equilibrium is more quickly restored and deviations from equilibrium due to system-wide shocks are shorter-lived. Although a long-run relationship exists among the crosscurrency basis swaps before the crisis and after the crisis periods, it is important to note, as our results have shown, that the long-run links have weakened since the crisis. Occurrence of the crisis has thus weakened the long run relationships of the cross-currency basis swap spreads.

Fig 2: Persistence profile and convergence to equilibrium - pre-crisis and post-crisis period

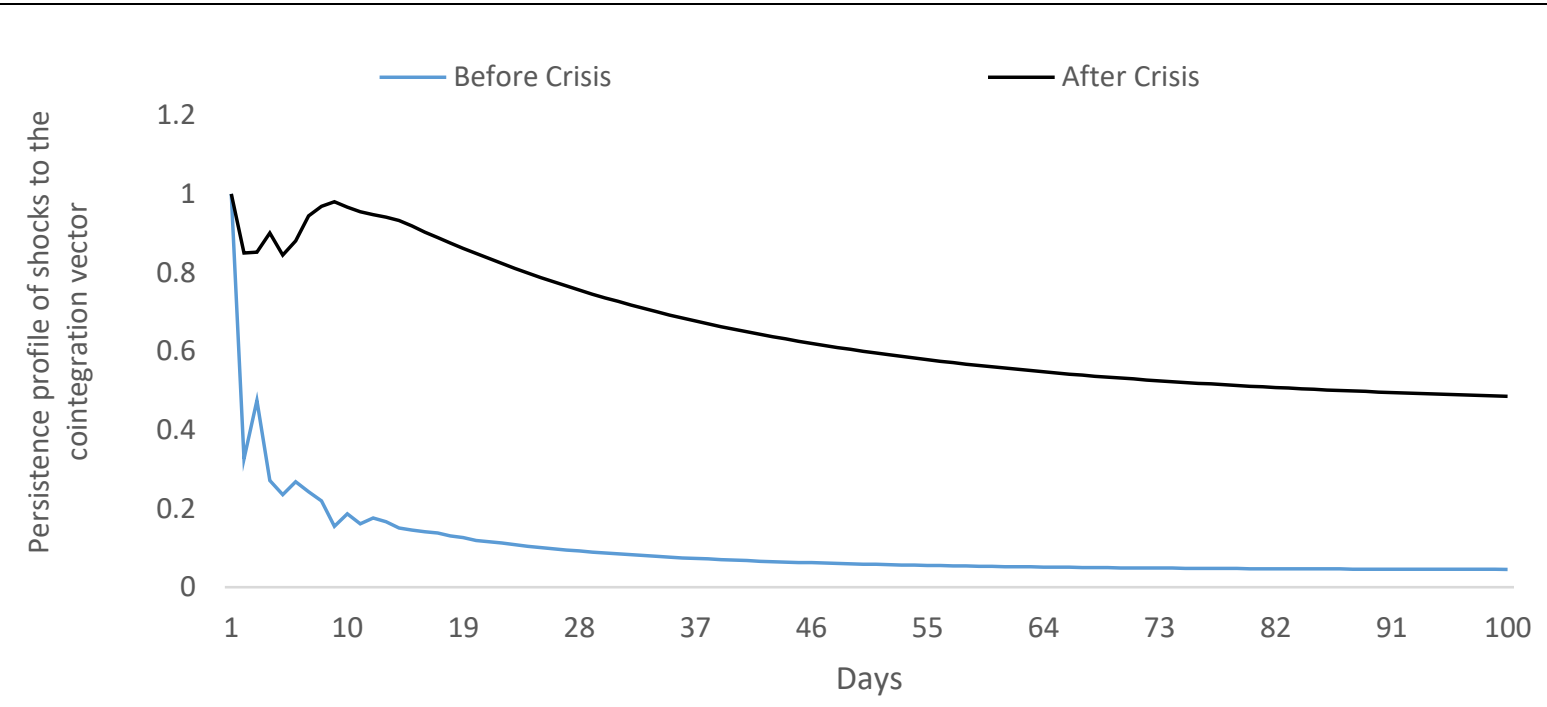


Furthermore, we also compute the theoretical average half-life of the speed of adjustment in the cointegrating vector, both in the pre- and post-crisis periods. This is the average time taken to achieve a 50-percent adjustment following a shock. The computed half-life for the pre-crisis period is 29 days, and 81 days for the post-crisis period, reiterating a slower adjustment towards equilibrium in the post-crisis period compared to the pre-crisis period. The cross-currency basis swaps wander off from their equilibrium path for more extended periods in the post-crisis period than in the precrisis period.

The finding that the long-run relationship among the cross-currency basis swaps is stronger in the pre-crisis period than after the crisis is worth further discussion. It is well-known that prior to the crisis, the cross-currency basis swap spreads were largely similar. Specifically, the covered interest rate parity held in most swap markets, especially the more liquid swap markets in Europe, and the magnitude of the cross-currency basis swap spreads was very close to zero or not significantly different from zero. In essence, the cross-currency basis swap spreads were close knit, shared similar characteristics and largely behaved in synchrony. However, with the commencement of the crisis, dollar shortages elevated around the world as those in possession of the dollar were unwilling to lend because their perception was that international banks have increasingly become more prone to risks. Hence, the magnitude of the cross-currency basis changed dramatically as swap market participants became much more willing to receive much less for providing their own currencies in the swap market in exchange for the USD, with the degree of demand for USD proportional to the level of overall economic and financial risks associated with the underlying currency. The divergence and widening of the cross-currency swap spreads persisted even after the crisis was over, and has not been arbitraged away perhaps due to the formulation of much stronger banking regulations, after the crisis, that has limited the amount of resources financial institutions can commit to non-core activities or risky ventures. The loosening of monetary policies in some developed economies, sometimes divergent fiscal and or monetary policies, de-synchronization of growth, increased issuance and participation of corporates and multilateral institutions in the global swap markets are all plausible factors responsible for the divergence of the basis. This turn of events possibly changed the dynamics and strength of integration among the swap markets and their associated cross-currency basis swap spreads.

Baran and Witzany (2017) strongly argues that the existence of the cross-currency basis swap spreads following the crisis has been often associated with deviations from the covered interest rate parity. Similar studies in the literature have routinely reached the same conclusion. Hence, our final word on the plausible reason why the cross-currency basis swap spreads appear less integrated in the long-run in the post-crisis period is that the CIP which held in the pre-crisis period and connected the swap markets like a magnet, forcing them together to unite more quickly in the event of a system-wide shock, have since been weakened and in most cases completely broken after the crisis. 


\subsection{Short Run Dynamic Linkages based on Forecast Error Variance Decomposition}

\subsubsection{Forecast Error Variance Decomposition Results (percentage)}

For each swap market, the forecast error variance decomposition provides the component of the forecast error variance in one market that is due to innovations in other markets. The variance decomposition separates the variation in a variable into the components emanating from shocks to other variables in the VAR system. Thus, the variance decomposition provides information about the relative importance that each random innovation has on variables in the VAR.

We perform the forecast error variance decompositions for both the pre-crisis and post-crisis periods. Tables 4 and 5 provide the 10-day, 20-day-ahead and 40-day-ahead forecast error variance decompositions of changes in the crosscurrency basis swap spreads. The tables report the decomposition of 10-day, 20-day, and 40-day ahead forecasts of the cross-currency swap spreads into fractions accounted for by innovations in all cross-currency basis swaps in the system. The results, discussed in detail below, provide a useful platform for identifying the main channels of influence in the nine-market dynamic system.

Table 4: Accounting Swap Market Innovations (Before Crisis)

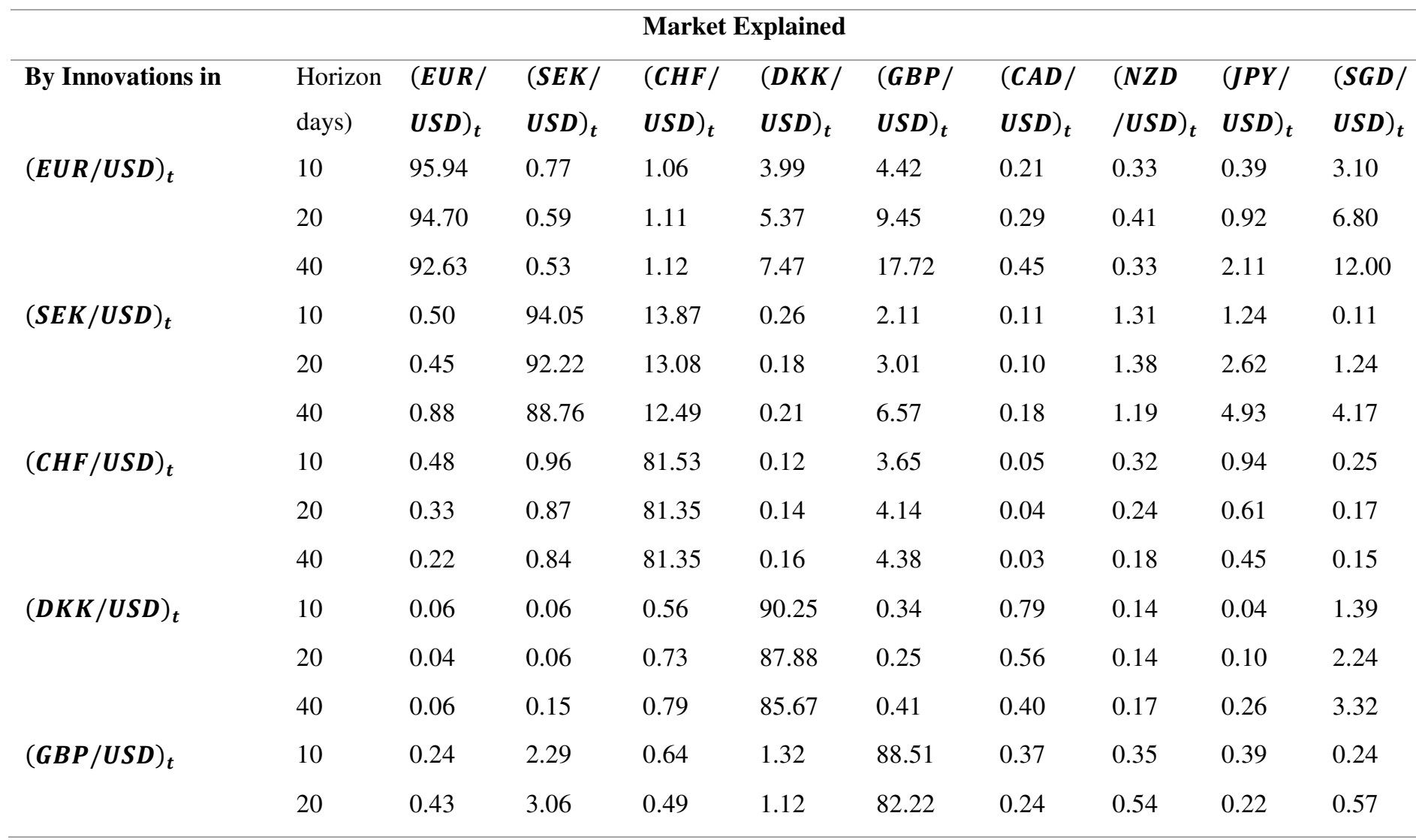




\begin{tabular}{|c|c|c|c|c|c|c|c|c|c|c|}
\hline & 40 & 0.85 & 4.84 & 0.28 & 0.79 & 70.03 & 0.14 & 0.74 & 0.15 & 1.42 \\
\hline \multirow[t]{3}{*}{$(C A D / U S D)_{t}$} & 10 & 0.62 & 0.30 & 1.29 & 0.23 & 0.32 & 97.55 & 0.10 & 0.24 & 2.20 \\
\hline & 20 & 0.77 & 0.31 & 1.69 & 0.47 & 0.43 & 97.90 & 0.08 & 0.32 & 1.52 \\
\hline & 40 & 0.94 & 0.36 & 2.05 & 0.62 & 0.48 & 97.92 & 0.06 & 0.34 & 1.15 \\
\hline \multirow[t]{3}{*}{$(N Z D / U S D)_{t}$} & 10 & 0.76 & 0.47 & 0.54 & 0.14 & 0.26 & 0.09 & 97.03 & 0.28 & 0.84 \\
\hline & 20 & 1.02 & 0.60 & 0.76 & 0.12 & 0.25 & 0.09 & 96.86 & 0.41 & 1.18 \\
\hline & 40 & 1.23 & 0.73 & 0.91 & 0.11 & 0.22 & 0.09 & 97.04 & 0.45 & 1.29 \\
\hline \multirow[t]{3}{*}{$(J P Y / U S D)_{t}$} & 10 & 0.99 & 0.20 & 0.27 & 1.98 & 0.09 & 0.13 & 0.07 & 96.23 & 0.16 \\
\hline & 20 & 1.43 & 0.28 & 0.41 & 2.63 & 0.06 & 0.21 & 0.05 & 94.39 & 0.35 \\
\hline & 40 & 1.90 & 0.43 & 0.51 & 2.89 & 0.06 & 0.25 & 0.03 & 90.71 & 0.35 \\
\hline \multirow[t]{4}{*}{$(S G D / U S D)_{t}$} & 10 & 0.41 & 0.91 & 0.24 & 1.72 & 0.31 & 0.70 & 0.34 & 0.25 & 91.70 \\
\hline & 20 & 0.83 & 2.01 & 0.38 & 2.09 & 0.20 & 0.57 & 0.30 & 0.41 & 85.93 \\
\hline & 40 & 1.30 & 3.37 & 0.47 & 2.08 & 0.13 & 0.53 & 0.25 & 0.61 & 76.16 \\
\hline & & & & Market & xplained & & & & & \\
\hline \multirow{5}{*}{$\begin{array}{l}\text { By Innovations in } \\
\text { All Other Markets }\end{array}$} & Horizon & $(E U R$ & $(\boldsymbol{S E K}$ & $(\mathrm{CHF} /$ & $(D K K /$ & $(\boldsymbol{G B P})$ & $(C A D$ & $(N Z D$ & $(J P Y$ & $(S G D)$ \\
\hline & days) & $/ U S D)_{t}$ & $/ U S D)_{t}$ & $U S D)_{t}$ & $U S D)_{t}$ & $U S D)_{t}$ & $/ U S D)_{t}$ & $/ U S D)_{t}$ & $/ U S D)_{t}$ & $U S D)_{t}$ \\
\hline & 10 & 4.06 & 5.95 & 18.47 & 9.75 & 11.49 & 2.45 & 2.97 & 3.77 & 8.30 \\
\hline & 20 & 5.30 & 7.78 & 18.65 & 12.12 & 17.78 & 2.10 & 3.14 & 5.61 & 14.07 \\
\hline & 40 & 7.37 & 11.24 & 18.65 & 14.33 & 29.97 & 2.08 & 2.96 & 9.29 & 23.84 \\
\hline
\end{tabular}

As can be seen in Tables 4 and 5, there are differences between the two periods regarding the inter and intra-dynamic linkages of the European swaps at the global and regional levels. Among all five European cross-currency swap spreads, the EUR/USD cross-currency swap turns out to be the least responsive to all other swaps in the system, either before or after the crisis. At 10-40 days ahead, the variations in the EUR/USD cross-currency swap spreads are explained predominantly (93-96\%) in the pre-crisis period and (95-87\%) in the post-crisis period by its own earlier innovations. Prior to the crisis, none of the other cross-currency swaps has an explanatory power of more than $2 \%$ in the variation of EUR/USD cross-currency basis. The self-explained proportion of variation in EUR/USD cross-currency swap decreases to $95-87 \%$ in the post-crisis period. Interestingly, we also observe a pattern of decreased importance of own swap shocks on variation of the cross-currency swaps in the post-crisis period for the other European cross-currency swaps.

Like the EUR/USD cross-currency swap, the variation in SEK/USD cross-currency swap is also explained largely by its earlier innovations in the pre-crisis period (94-89\%). Before the crisis, only GBP/USD cross-currency swaps (2-5\%) and to a lower extent SGD/USD cross-currency swap (0.91-3.4\%) accounts for more than $1 \%$ of the variation in SEK/USD cross-currency swap. The reduction in importance of its own shocks from (59-47\%), to around (35-42\%), 
after the crisis is quite notable. By contrast, the EUR/USD and CHF/USD cross-currency swaps have increased their explanatory power and influence on the SEK/USD cross-currency basis after the crisis. In particular, innovations in EUR/USD and CHF/USD cross-currency swaps explain about (37-42\%) and (2-5\%) of the variations in the SEK/USD cross-currency swap after the crisis, compared to less than $1 \%$ at all horizons in the pre-crisis period.

Table 5: Accounting Swap Market Innovations (After Crisis)

\section{Market Explained}

\begin{tabular}{|c|c|c|c|c|c|c|c|c|c|c|}
\hline By Innovations in & $\begin{array}{l}\text { Horizon } \\
\text { days) }\end{array}$ & $\begin{array}{l}(E U R / \\
U S D)_{t}\end{array}$ & $\begin{array}{l}(S E K / \\
U S D)_{t}\end{array}$ & $\begin{array}{l}(\mathrm{CHF} / \\
\mathrm{USD})_{t}\end{array}$ & $\begin{array}{l}(D K K / \\
U S D)_{t}\end{array}$ & $\begin{array}{l}(G B P / \\
U S D)_{t}\end{array}$ & $\begin{array}{l}(C A D / \\
U S D)_{t}\end{array}$ & $\begin{array}{l}(N Z D / \\
U S D)_{t}\end{array}$ & $\begin{array}{l}(J P Y \\
/ U S D)_{t}\end{array}$ & $\begin{array}{l}(S G D / \\
U S D)_{t}\end{array}$ \\
\hline \multirow{3}{*}{$(E U R / U S D)_{t}$} & 10 & 94.79 & 36.91 & 34.43 & 53.51 & 24.42 & 1.42 & 0.16 & 10.72 & 0.16 \\
\hline & 20 & 91.64 & 40.67 & 40.48 & 58.06 & 25.60 & 2.72 & 0.13 & 13.68 & 0.11 \\
\hline & 40 & 86.61 & 41.57 & 43.66 & 58.22 & 26.31 & 3.41 & 0.11 & 15.34 & 0.11 \\
\hline \multirow{3}{*}{$(S E K / U S D)_{t}$} & 10 & 1.16 & 58.96 & 0.06 & 0.11 & 0.73 & 0.43 & 0.04 & 0.45 & 2.31 \\
\hline & 20 & 1.14 & 52.00 & 0.04 & 0.07 & 0.48 & 0.62 & 0.02 & 0.52 & 3.20 \\
\hline & 40 & 1.13 & 47.07 & 0.03 & 0.05 & 0.34 & 0.82 & 0.02 & 0.57 & 3.79 \\
\hline \multirow[t]{3}{*}{$(C H F / U S D)_{t}$} & 10 & 2.36 & 1.63 & 63.97 & 3.20 & 5.66 & 0.18 & 0.26 & 5.56 & 1.84 \\
\hline & 20 & 4.44 & 3.11 & 58.25 & 5.13 & 7.51 & 0.70 & 0.33 & 7.86 & 3.84 \\
\hline & 40 & 7.41 & 5.11 & 55.29 & 7.52 & 9.71 & 2.28 & 0.48 & 10.65 & 7.82 \\
\hline \multirow[t]{3}{*}{$(D K K / U S D)_{t}$} & 10 & 0.20 & 0.37 & 0.24 & 41.52 & 0.54 & 0.68 & 0.15 & 0.29 & 0.74 \\
\hline & 20 & 0.34 & 0.54 & 0.31 & 34.42 & 0.51 & 0.74 & 0.21 & 0.45 & 0.87 \\
\hline & 40 & 0.56 & 0.75 & 0.32 & 30.87 & 0.56 & 0.61 & 0.27 & 0.64 & 1.24 \\
\hline \multirow{3}{*}{$(G B P / U S D)_{t}$} & 10 & 0.07 & 0.21 & 0.49 & 0.06 & 65.40 & 0.20 & 0.32 & 0.31 & 3.07 \\
\hline & 20 & 0.04 & 0.22 & 0.34 & 0.04 & 60.76 & 0.47 & 0.49 & 0.18 & 5.38 \\
\hline & 40 & 0.13 & 0.12 & 0.24 & 0.14 & 55.87 & 1.17 & 0.66 & 0.19 & 8.35 \\
\hline \multirow[t]{3}{*}{$(C A D / U S D)_{t}$} & 10 & 0.04 & 0.25 & 0.26 & 0.09 & 1.79 & 96.53 & 0.03 & 0.62 & 0.34 \\
\hline & 20 & 0.22 & 0.72 & 0.16 & 0.06 & 3.22 & 93.75 & 0.05 & 1.23 & 0.37 \\
\hline & 40 & 0.84 & 1.52 & 0.11 & 0.24 & 4.64 & 89.66 & 0.10 & 2.04 & 1.13 \\
\hline \multirow[t]{3}{*}{$(N Z D / U S D)_{t}$} & 10 & 0.49 & 0.55 & 0.45 & 0.81 & 0.25 & 0.03 & 98.14 & 0.12 & 0.16 \\
\hline & 20 & 0.49 & 0.70 & 0.32 & 0.97 & 0.21 & 0.10 & 97.67 & 0.18 & 0.10 \\
\hline & 40 & 0.45 & 0.71 & 0.26 & 0.97 & 0.18 & 0.16 & 97.18 & 0.20 & 0.09 \\
\hline \multirow[t]{3}{*}{$(J P Y / U S D)_{t}$} & 10 & 0.28 & 0.30 & 0.04 & 0.39 & 0.43 & 0.16 & 0.78 & 81.13 & 0.38 \\
\hline & 20 & 0.50 & 0.57 & 0.05 & 0.64 & 0.46 & 0.25 & 0.97 & 75.13 & 0.28 \\
\hline & 40 & 0.74 & 0.79 & 0.05 & 0.84 & 0.53 & 0.42 & 1.01 & 69.86 & 0.16 \\
\hline \multirow[t]{3}{*}{$(S G D / U S D)_{t}$} & 10 & 0.60 & 0.81 & 0.05 & 0.31 & 0.78 & 0.37 & 0.12 & 0.79 & 91.01 \\
\hline & 20 & 1.18 & 1.49 & 0.05 & 0.60 & 1.25 & 0.66 & 0.11 & 0.77 & 85.85 \\
\hline & 40 & 2.13 & 2.37 & 0.04 & 1.15 & 1.86 & 1.48 & 0.15 & 0.51 & 77.31 \\
\hline
\end{tabular}




\section{Market Explained}

$\begin{array}{lllllllllll}\text { By Innovations in } & \text { Horizon } & (\boldsymbol{E U R} & (\boldsymbol{S E K} & (\boldsymbol{C H F} / & (\boldsymbol{D K K} / & (\boldsymbol{G B P} / & (\boldsymbol{C A D} / & (\boldsymbol{N Z D} & (\boldsymbol{U P Y} / & (\boldsymbol{S G D} / \\ \text { All Other Markets } & \text { days }) & / \boldsymbol{U S D})_{\boldsymbol{t}} & / \boldsymbol{U S D})_{\boldsymbol{t}} & \boldsymbol{U S D})_{\boldsymbol{t}} & \boldsymbol{U S D})_{\boldsymbol{t}} & \boldsymbol{U S D})_{\boldsymbol{t}} & \boldsymbol{U S D})_{\boldsymbol{t}} & / \boldsymbol{U S D})_{\boldsymbol{t}} & \boldsymbol{U S D})_{\boldsymbol{t}} & \boldsymbol{U S D})_{\boldsymbol{t}} \\ & 10 & 5.21 & 41.04 & 36.03 & 58.48 & 34.60 & 3.47 & 1.86 & 18.87 & 8.99 \\ & 20 & 8.36 & 48.00 & 41.75 & 65.58 & 39.24 & 6.25 & 2.33 & 24.87 & 14.15 \\ & 40 & 13.39 & 52.93 & 44.71 & 69.13 & 44.13 & 10.34 & 2.82 & 30.14 & 22.69\end{array}$

Moving to CHF/USD cross-currency swap, the swap appears to be driven mostly by its own innovations (82-81\%), SEK/USD swap (about 14-12\%), and to a less extent by the EUR/USD swap (1-1\%) and CAD/USD swap (1-2\%) in the pre-crisis period. After the crisis, the influence of the EUR/USD cross-currency swap on CHF/USD swap increases significantly to (34-44\%) while the influences of the other cross-currency swaps shrink considerably. Mostly notably, the variability of the CHF/USD basis due to innovations in SEK/USD basis decrease sharply to nearly 0\% across all the horizons considered while variation in CHF/USD due to own innovations falls to (64-55\%).

Turning to the DKK/USD, the decrease in the importance of its own market shocks from (90-86\%) in the pre-crisis period to $(42-31 \%)$ after the crisis is the largest among all cross-currency swap spreads represented in our sample. The EUR/USD and CHF/USD cross-currency swaps can considerably explain (54-58\%) and (3-8\%), respectively, of the variation in DKK/USD cross-currency swap after the crisis compared to the explanation of(4-7\%), (2-3\%) and (2-2\%) of the variability in DKK/USD cross-currency basis by innovations in JPY/USD and SGD/USD cross-currency swap respectively in the pre-crisis period. Thus, the influence of all other cross-currency swaps on DKK/USD cross-currency swap reduced noticeably after the crisis, but the influence of the EUR/USD cross-currency swap increased by several folds post-crisis and becomes dominant.

With respect to GBP/USD cross-currency swap, it appears to be driven mostly by its own innovations (89-70\%) and by innovations in the EUR/USD cross-currency swap (4-18\%), SEK/USD swap (2-7\%) and to some extent by innovations in CHF/USD swap (4-4\%) in the pre-crisis period. As with other European cross-currency swaps, in the post-crisis period, the influence of EUR/USD cross-currency swap surged to (24-26\%), SEK/USD shrinks to $0 \%$ while the influence of CHF/USD cross-currency swap also rose to (6-10\%). Interestingly, the CAD/USD cross-currency swap which has no influence on the variability of the GBP/USD swap in the pre-crisis period, now explains (2-5\%) of the variability of GBP/USD cross-currency swap. The influence of own innovations on the variability of GBP/USD crosscurrency swap declines to $(65-56 \%)$ in the post-crisis era.

As a general pattern, the variability of the other cross-currency swaps is explained by their own innovations in the precrisis period - CAD/USD (98-98\%), NZD/USD (97-97\%) and JPY/USD (96-91\%) - except for the SGD/USD swap which is influenced by itself $(92-76 \%)$ but also by innovations the EUR/USD swap (3-12\%), SEK/USD (0-4\%), 
DKK/USD (1-3\%), GBP/USD (0-2\%), and CAD/USD and NZD/USD cross-currency swap (both 0-1\%). The EUR/USD and SEK/USD cross-currency swaps also exert some influence on JPY/USD basis at (0-2\%) and (1-5\%) respectively while the SEK/USD swap has minor influence (1-1\%) on the variability of the NZD/USD swap. In the post-crisis period, the large self-influence of the non-European cross-currency swaps remains mostly unchanged as the variability of CAD/USD, NZD/USD, JPY/USD and SGD/USD cross-currency swap spreads due to their innovations are $(97-90 \%),(98-97 \%),(81-69 \%)$ and $(91-77 \%)$. Worthy of mention is the spike in the influence of the EUR/USD (11-15\%) and CHF/USD cross-currency swap (6-11\%) on the JPY/USD cross-currency swap, and the contribution of innovations in SEK/USD swap (2-4\%), CHF/USD swap (2-8\%) and GBP/USD swap (3-8\%) to the variability of SGD/USD swap in the post crisis period.

Fig 3: Response to shocks in other swap markets 40 days later

Response to shocks in other swap markets 40 days later

80

70

60

50

40

30

20

10

0
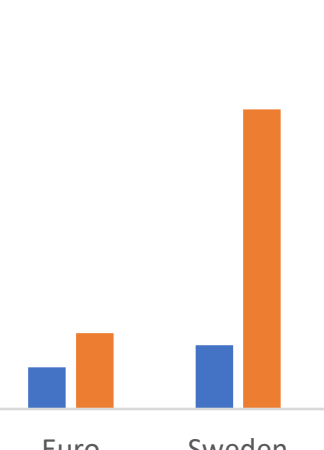

Sweden
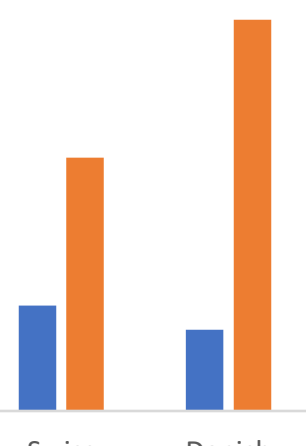

Danish

Sterling

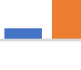

CAD

NZ

JPY

- Total variability explained by innovations in other markets: before crisis

- Total variability explained by innovations in other markets: after crisis

To summarize, the CAD/USD and NZD/USD cross-currency swap spreads are the most uninfluenced by other crosscurrency swap spreads analyzed in this paper, at all horizons, and this finding is true both in the pre-crisis and postcrisis periods. The EUR/USD swap basis by far has the most single influence on the other cross-currency swap spreads both in the pre-crisis and post-crisis periods; the influence of the EUR/USD cross-currency swap spread on the rest becomes elevated and significantly stronger after the crisis. We also find that the percentage of explained variation in each European cross-currency swap spread by innovations in other cross currency swap spreads is much higher in the post-crisis period than in the pre-crisis period and, in general, except for SGD/USD swap, the percentage of explained 
variations of all the cross-currency basis swap spreads analyzed in this paper increases significantly after the crisis. This result implies that the crisis caused European currency basis swap spreads to be more responsive to external shocks to swaps within the region and the rest of the world. It also suggests that some cross-currency basis swap spreads from the rest of the world appear to have become more responsive to European cross-currency basis swap spreads, notably the EUR/USD basis. We also find that the SEK/USD basis swap spread exerts considerable influence on all other European cross-currency swap spreads, particularly after the crisis.

An interesting finding from the analysis of the short-run dynamic linkages presented in this paper is that: not only did the crisis lead to an increase in the linkages of European cross-currency swaps with those from other regions of the world, particularly JPY/USD and SGD/USD swaps, it has also enabled these swap spreads to be more responsive to innovations in European swaps, particularly the EUR/USD, SEK/USD, CHF/USD and GBP/USD cross-currency swap spreads.

\subsection{Robustness Check}

To concretize the validity of our findings, we perform several robustness checks for the results reported in the previous section. First, we reexamine the above forecast error variance decompositions by considering alternative orderings of the variables. Reordering the cross-currency basis swap spreads in the VAR system is a well-known empirical strategy to check whether results of forecast error variance decomposition are highly sensitive to alternative orderings of variables. To achieve this, we reverse the previous ordering, from top to bottom, giving a new ordering as follows: SGD/USD, JPY/USD, NZD/USD, CAD/USD, GBP/USD, DKK/USD, CHF/USD, SEK/USD and EUR/USD crosscurrency swap spreads. For a direct comparison with the previous variance decompositions, we also conduct the forecast error variance decompositions based on the reordered variables for both the pre-crisis and post-crisis periods and report the results in Tables 6 and 7. Second, we conduct a generalized impulse response analysis which allows us to examine the path or direction of the impact of one variable on the other variable following a shock to each variable in the VAR system. Lastly, we implement a 52-week rolling variance decomposition analysis as an additional robustness check on the results for the variance decompositions obtained in the pre-crisis and post-crisis periods. This helps to provide a systematic analysis of robustness of results regarding the possibility of sub-sample instability in periods covering the pre-crisis and post-crisis era. 
Table 6: Robust forecast error variance (pre-crisis period)

\begin{tabular}{|c|c|c|c|c|c|c|c|c|c|c|}
\hline & & & & Market & Explained & & & & & \\
\hline By Innovations in & $\begin{array}{l}\text { Horizon } \\
\text { days) }\end{array}$ & $\begin{array}{l}(E U R / \\
U S D)_{t}\end{array}$ & $\begin{array}{l}(S E K / \\
U S D)_{t}\end{array}$ & $\begin{array}{l}(C H F / \\
U S D)_{t}\end{array}$ & $\begin{array}{l}(D K K / \\
U S D)_{t}\end{array}$ & $\begin{array}{l}(G B P / \\
U S D)_{t}\end{array}$ & $\begin{array}{l}(C A D / \\
U S D)_{t}\end{array}$ & $\begin{array}{l}(N Z D / \\
U S D)_{t}\end{array}$ & $\begin{array}{l}(J P Y / \\
U S D)_{t}\end{array}$ & $\begin{array}{l}(S G D / \\
U S D)_{t}\end{array}$ \\
\hline$(E U R / U S D)_{t}$ & 10 & 95.58 & 0.73 & 1.05 & 3.80 & 4.32 & 0.24 & 0.36 & 0.40 & 2.07 \\
\hline & 20 & 94.09 & 0.55 & 1.08 & 5.11 & 9.36 & 0.35 & 0.44 & 0.95 & 5.20 \\
\hline & 40 & 91.80 & 0.55 & 1.09 & 7.15 & 17.67 & 0.54 & 0.36 & 2.17 & 9.90 \\
\hline$(S E K / U S D)_{t}$ & 10 & 0.50 & 93.87 & 13.85 & 0.28 & 2.10 & 0.12 & 1.34 & 1.25 & 0.07 \\
\hline & 20 & 0.46 & 91.87 & 13.05 & 0.19 & 3.01 & 0.12 & 1.41 & 2.64 & 1.01 \\
\hline & 40 & 0.91 & 88.26 & 12.45 & 0.21 & 6.58 & 0.21 & 1.22 & 4.98 & 3.69 \\
\hline$(C H F / U S D)_{t}$ & 10 & 0.48 & 0.95 & 81.56 & 0.13 & 3.67 & 0.05 & 0.31 & 0.93 & 0.25 \\
\hline & 20 & 0.32 & 0.85 & 81.43 & 0.15 & 4.16 & 0.03 & 0.23 & 0.60 & 0.21 \\
\hline & 40 & 0.21 & 0.81 & 81.46 & 0.18 & 4.39 & 0.03 & 0.17 & 0.44 & 0.22 \\
\hline$(D K K / U S D)_{t}$ & 10 & 0.06 & 0.06 & 0.55 & 89.98 & 0.34 & 0.74 & 0.13 & 0.04 & 1.08 \\
\hline & 20 & 0.04 & 0.06 & 0.72 & 87.52 & 0.25 & 0.52 & 0.13 & 0.11 & 1.84 \\
\hline & 40 & 0.06 & 0.17 & 0.78 & 85.28 & 0.41 & 0.36 & 0.16 & 0.27 & 2.85 \\
\hline$(G B P / U S D)_{t}$ & 10 & 0.23 & 2.24 & 0.65 & 1.27 & 88.35 & 0.37 & 0.37 & 0.40 & 0.41 \\
\hline & 20 & 0.41 & 2.97 & 0.49 & 1.06 & 82.10 & 0.25 & 0.57 & 0.22 & 0.87 \\
\hline & 40 & 0.81 & 4.67 & 0.29 & 0.74 & 70.00 & 0.16 & 0.77 & 0.14 & 1.88 \\
\hline$(C A D / U S D)_{t}$ & 10 & 0.71 & 0.36 & 1.37 & 0.35 & 0.36 & 94.24 & 0.11 & 0.27 & 1.60 \\
\hline & 20 & 0.95 & 0.47 & 1.85 & 0.71 & 0.45 & 94.68 & 0.07 & 0.39 & 2.83 \\
\hline & 40 & 1.21 & 0.64 & 2.27 & 0.90 & 0.47 & 94.70 & 0.04 & 0.43 & 3.29 \\
\hline$(N Z D / U S D)_{t}$ & 10 & 0.74 & 0.45 & 0.52 & 0.12 & 0.27 & 0.10 & 96.67 & 0.28 & 0.44 \\
\hline & 20 & 0.97 & 0.55 & 0.73 & 0.10 & 0.25 & 0.10 & 96.50 & 0.39 & 0.69 \\
\hline & 40 & 1.16 & 0.65 & 0.88 & 0.09 & 0.22 & 0.10 & 96.69 & 0.43 & 0.79 \\
\hline$(J P Y / U S D)_{t}$ & 10 & 0.98 & 0.19 & 0.27 & 1.95 & 0.09 & 0.14 & 0.07 & 96.28 & 0.12 \\
\hline & 20 & 1.41 & 0.26 & 0.40 & 2.59 & 0.06 & 0.22 & 0.05 & 94.47 & 0.28 \\
\hline & 40 & 1.87 & 0.41 & 0.51 & 2.84 & 0.06 & 0.26 & 0.03 & 90.83 & 0.28 \\
\hline$(S G D / U S D)_{t}$ & 10 & 0.73 & 1.14 & 0.17 & 2.13 & 0.50 & 4.02 & 0.63 & 0.16 & 93.95 \\
\hline & 20 & 1.34 & 2.42 & 0.25 & 2.57 & 0.36 & 3.72 & 0.60 & 0.22 & 87.05 \\
\hline & 40 & 1.96 & 3.86 & 0.29 & 2.61 & 0.20 & 3.64 & 0.55 & 0.31 & 77.09 \\
\hline & & & & Market & Explained & & & & & \\
\hline By Innovations in & Horizon & $(\boldsymbol{E} \boldsymbol{U} \boldsymbol{R}$ & $(\boldsymbol{S E K}$ & $(\mathrm{CHF})$ & $(D K K)$ & $(\boldsymbol{G B P}$ & $(C A D)$ & $(N Z D /$ & $(J P Y$ & $(\boldsymbol{S G D})$ \\
\hline All Other Markets & days) & $/ U S D)_{t}$ & $/ U S D)_{t}$ & $U S D)_{t}$ & $U S D)_{t}$ & $/ U S D)_{t}$ & $U S D)_{t}$ & $U S D)_{t}$ & $/ U S D)_{t}$ & $U S D)_{t}$ \\
\hline & 10 & 4.42 & 6.13 & 18.44 & 10.02 & 11.65 & 5.76 & 3.33 & 3.72 & 6.05 \\
\hline & 20 & 5.91 & 8.13 & 18.57 & 12.48 & 17.90 & 5.32 & 3.50 & 5.53 & 12.95 \\
\hline & 40 & 8.20 & 11.74 & 18.54 & 14.72 & 30.00 & 5.30 & 3.31 & 9.17 & 22.91 \\
\hline
\end{tabular}


Table 7: Robust forecast error variance (post-crisis period)

\begin{tabular}{|c|c|c|c|c|c|c|c|c|c|c|}
\hline & & & & Market & Explained & & & & & \\
\hline $\begin{array}{l}\text { By Innovations in } \\
(E U R / U S D)_{t}\end{array}$ & $\begin{array}{l}\begin{array}{l}\text { Horizon } \\
\text { days) }\end{array} \\
10\end{array}$ & $\begin{array}{l}(E U R / \\
U S D)_{t} \\
94.80\end{array}$ & $\begin{array}{l}(\boldsymbol{S E K} \\
/ \boldsymbol{U S D})_{t} \\
36.92\end{array}$ & $\begin{array}{l}(\boldsymbol{C H F} \\
/ \boldsymbol{U S D})_{t} \\
34.43\end{array}$ & $\begin{array}{l}(D K K \\
/ U S D)_{t} \\
53.51\end{array}$ & $\begin{array}{l}(\boldsymbol{G B P} / \\
\boldsymbol{U S D})_{t} \\
24.42\end{array}$ & $\begin{array}{l}(\boldsymbol{C A D}) \\
/ \boldsymbol{U S D})_{t} \\
1.42\end{array}$ & $\begin{array}{l}(N Z D / \\
U S D)_{t} \\
0.16\end{array}$ & $\begin{array}{l}(J P Y / \\
U S D)_{t} \\
10.72\end{array}$ & $\begin{array}{l}(S G D / \\
U S D)_{t} \\
0.16\end{array}$ \\
\hline & 20 & 91.65 & 40.68 & 40.48 & 58.07 & 25.61 & 2.72 & 0.13 & 13.68 & 0.11 \\
\hline & 40 & 86.62 & 41.58 & 43.66 & 58.23 & 26.32 & 3.41 & 0.11 & 15.33 & 0.11 \\
\hline$(S E K / U S D)_{t}$ & 10 & 1.24 & 58.09 & 0.07 & 0.12 & 0.67 & 0.48 & 0.04 & 0.36 & 0.94 \\
\hline & 20 & 1.26 & 50.93 & 0.04 & 0.08 & 0.41 & 0.71 & 0.02 & 0.42 & 1.52 \\
\hline & 40 & 1.29 & 45.80 & 0.03 & 0.07 & 0.27 & 0.96 & 0.01 & 0.47 & 1.97 \\
\hline$(C H F / U S D)_{t}$ & 10 & 2.50 & 1.76 & 63.87 & 3.25 & 5.93 & 0.21 & 0.29 & 5.24 & 0.69 \\
\hline & 20 & 4.70 & 3.35 & 58.19 & 5.26 & 7.90 & 0.79 & 0.36 & 7.46 & 2.09 \\
\hline & 40 & 7.86 & 5.51 & 55.23 & 7.77 & 10.25 & 2.52 & 0.53 & 10.26 & 5.30 \\
\hline$(\boldsymbol{D} K \boldsymbol{K} / \boldsymbol{U} S \boldsymbol{D})_{t}$ & 10 & 0.23 & 0.41 & 0.25 & 41.64 & 0.58 & 0.64 & 0.16 & 0.25 & 0.29 \\
\hline & 20 & 0.39 & 0.61 & 0.32 & 34.66 & 0.57 & 0.68 & 0.23 & 0.39 & 0.35 \\
\hline & 40 & 0.65 & 0.86 & 0.33 & 31.24 & 0.65 & 0.54 & 0.30 & 0.59 & 0.61 \\
\hline$(G B P / U S D)_{t}$ & 10 & 0.07 & 0.20 & 0.49 & 0.06 & 65.06 & 0.21 & 0.33 & 0.33 & 2.44 \\
\hline & 20 & 0.04 & 0.19 & 0.34 & 0.05 & 60.33 & 0.50 & 0.51 & 0.18 & 4.46 \\
\hline & 40 & 0.15 & 0.10 & 0.24 & 0.16 & 55.35 & 1.25 & 0.69 & 0.19 & 7.21 \\
\hline$(C A D / U S D)_{t}$ & 10 & 0.04 & 0.26 & 0.27 & 0.09 & 1.82 & 96.38 & 0.04 & 0.61 & 0.25 \\
\hline & 20 & 0.23 & 0.74 & 0.16 & 0.07 & 3.27 & 93.56 & 0.06 & 1.20 & 0.27 \\
\hline & 40 & 0.87 & 1.56 & 0.11 & 0.25 & 4.71 & 89.38 & 0.11 & 2.01 & 0.95 \\
\hline$(N Z D / U S D)_{t}$ & 10 & 0.51 & 0.58 & 0.45 & 0.83 & 0.27 & 0.03 & 97.97 & 0.11 & 0.29 \\
\hline & 20 & 0.53 & 0.75 & 0.32 & 1.00 & 0.23 & 0.09 & 97.49 & 0.16 & 0.22 \\
\hline & 40 & 0.49 & 0.77 & 0.26 & 1.01 & 0.21 & 0.14 & 96.98 & 0.18 & 0.21 \\
\hline$(J P Y / U S D)_{t}$ & 10 & 0.26 & 0.28 & 0.04 & 0.38 & 0.41 & 0.15 & 0.79 & 80.77 & 0.18 \\
\hline & 20 & 0.47 & 0.53 & 0.05 & 0.61 & 0.43 & 0.23 & 0.99 & 74.77 & 0.11 \\
\hline & 40 & 0.68 & 0.73 & 0.05 & 0.80 & 0.48 & 0.38 & 1.03 & 69.57 & 0.06 \\
\hline$(S G D / U S D)_{t}$ & 10 & 0.35 & 1.50 & 0.13 & 0.12 & 0.84 & 0.47 & 0.22 & 1.62 & 94.77 \\
\hline & 20 & 0.74 & 2.23 & 0.10 & 0.21 & 1.25 & 0.73 & 0.21 & 1.73 & 90.86 \\
\hline & 40 & 1.38 & 3.09 & 0.08 & 0.47 & 1.76 & 1.43 & 0.25 & 1.40 & 83.59 \\
\hline & & & & Market & Explained & & & & & \\
\hline By Innovations in & Horizon & $(\boldsymbol{E} \boldsymbol{U} \boldsymbol{R}$ & $(S E K$ & $(\boldsymbol{C H F}$ & $(D K K$ & $(\boldsymbol{G B P}$ & $(C A D$ & $(N Z D$ & $(J P Y$ & $(\boldsymbol{S G D})$ \\
\hline All Other Markets & days) & $/ U S D)_{t}$ & $/ U S D)_{t}$ & $/ U S D)_{t}$ & $/ U S D)_{t}$ & $/ U S D)_{t}$ & $/ U S D)_{t}$ & $/ U S D)_{t}$ & $/ U S D)_{t}$ & $U S D)_{t}$ \\
\hline & 10 & 5.20 & 41.91 & 36.13 & 58.36 & 34.94 & 3.62 & 2.03 & 19.23 & 5.23 \\
\hline & 20 & 8.35 & 49.07 & 41.81 & 65.34 & 39.67 & 6.44 & 2.51 & 25.23 & 9.14 \\
\hline & 40 & 13.38 & 54.20 & 44.77 & 68.76 & 44.65 & 10.62 & 3.02 & 30.43 & 16.41 \\
\hline
\end{tabular}


For the generalized impulse response analysis, the results are summarized in Table 8 below.

Table 8: Generalized Impulse Response Functions (Percentage) - Before

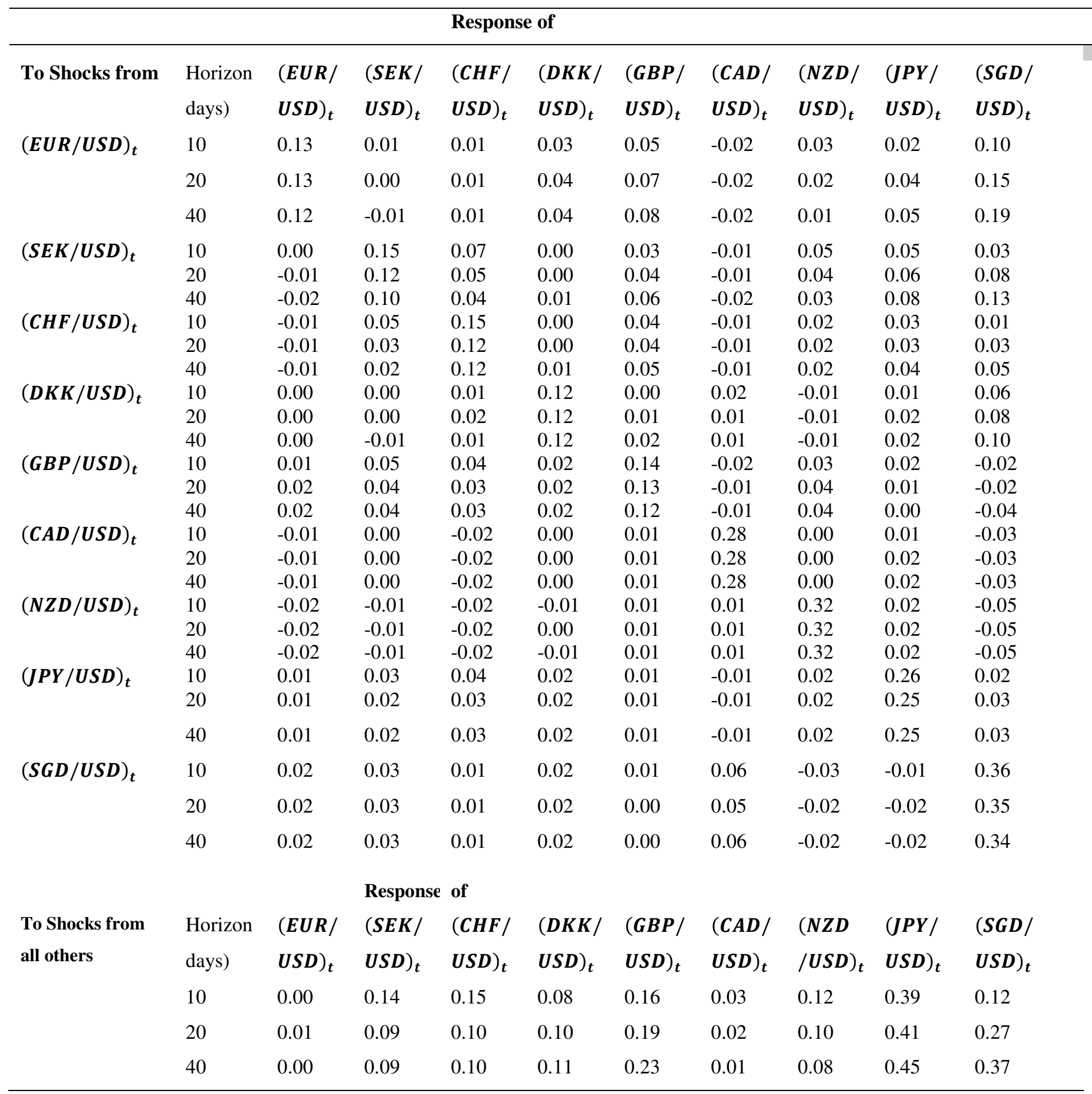


Table 9: Generalized Impulse Response Functions (Percentage)- After

\section{Response of}

\begin{tabular}{|c|c|c|c|c|c|c|c|c|c|c|}
\hline \multirow[t]{2}{*}{ To Shocks from } & Horizon & $(E U R /$ & $(S E K /$ & $(\mathrm{CHF})$ & $(D K K /$ & $(\boldsymbol{G B P})$ & $(C A D)$ & $(N Z D /$ & $(J P Y)$ & $(S G D /$ \\
\hline & days) & $U S D)_{t}$ & $U S D)_{t}$ & $U S D)_{t}$ & $U S D)_{t}$ & $U S D)_{t}$ & $U S D)_{t}$ & $U S D)_{t}$ & $U S D)_{t}$ & $U S D)_{t}$ \\
\hline \multirow[t]{3}{*}{$(E U R / U S D)_{t}$} & 10 & 0.94 & 0.37 & 0.73 & 0.85 & 0.33 & 0.09 & 0.02 & 0.49 & 0.01 \\
\hline & 20 & 0.95 & 0.38 & 0.73 & 0.88 & 0.33 & 0.09 & 0.02 & 0.52 & 0.01 \\
\hline & 40 & 0.96 & 0.39 & 0.73 & 0.89 & 0.34 & 0.09 & 0.02 & 0.53 & 0.02 \\
\hline \multirow[t]{3}{*}{$(S E K / U S D)_{t}$} & 10 & 0.16 & 0.48 & 0.21 & 0.21 & 0.12 & 0.06 & 0.00 & 0.04 & -0.11 \\
\hline & 20 & 0.15 & 0.48 & 0.21 & 0.22 & 0.12 & 0.07 & 0.00 & 0.05 & -0.11 \\
\hline & 40 & 0.15 & 0.48 & 0.21 & 0.22 & 0.12 & 0.07 & 0.00 & 0.04 & -0.11 \\
\hline \multirow[t]{3}{*}{$(C H F / U S D)_{t}$} & 10 & 0.49 & 0.24 & 0.94 & 0.51 & 0.28 & 0.00 & -0.02 & 0.50 & 0.11 \\
\hline & 20 & 0.56 & 0.27 & 0.96 & 0.58 & 0.30 & -0.03 & -0.03 & 0.56 & 0.15 \\
\hline & 40 & 0.64 & 0.31 & 0.96 & 0.65 & 0.33 & -0.07 & -0.04 & 0.63 & 0.21 \\
\hline \multirow[t]{3}{*}{$(D K K / U S D)_{t}$} & 10 & 0.35 & 0.18 & 0.36 & 0.84 & 0.15 & 0.06 & -0.02 & 0.26 & 0.05 \\
\hline & 20 & 0.38 & 0.19 & 0.35 & 0.87 & 0.17 & 0.06 & -0.03 & 0.29 & 0.07 \\
\hline & 40 & 0.42 & 0.21 & 0.35 & 0.90 & 0.18 & 0.04 & -0.03 & 0.32 & 0.10 \\
\hline \multirow[t]{3}{*}{$(G B P / U S D)_{t}$} & 10 & 0.34 & 0.24 & 0.29 & 0.35 & 0.59 & 0.06 & 0.04 & 0.19 & -0.14 \\
\hline & 20 & 0.31 & 0.23 & 0.29 & 0.34 & 0.58 & 0.08 & 0.04 & 0.17 & -0.16 \\
\hline & 40 & 0.28 & 0.22 & 0.29 & 0.32 & 0.57 & 0.09 & 0.05 & 0.15 & -0.18 \\
\hline \multirow[t]{3}{*}{$(C A D / U S D)_{t}$} & 10 & 0.08 & 0.07 & 0.08 & 0.04 & 0.15 & 0.45 & -0.02 & 0.18 & 0.01 \\
\hline & 20 & 0.13 & 0.10 & 0.07 & 0.09 & 0.17 & 0.43 & -0.02 & 0.21 & 0.05 \\
\hline & 40 & 0.20 & 0.13 & 0.07 & 0.14 & 0.19 & 0.40 & -0.02 & 0.26 & 0.10 \\
\hline \multirow[t]{3}{*}{$(N Z D / U S D)_{t}$} & 10 & 0.05 & 0.05 & -0.11 & 0.10 & 0.02 & 0.02 & 0.55 & 0.03 & -0.01 \\
\hline & 20 & 0.04 & 0.05 & -0.10 & 0.08 & 0.01 & 0.03 & 0.55 & 0.03 & -0.03 \\
\hline & 40 & 0.03 & 0.05 & -0.10 & 0.07 & 0.01 & 0.03 & 0.55 & 0.02 & -0.03 \\
\hline \multirow[t]{3}{*}{$(J P Y / U S D)_{t}$} & 10 & 0.13 & 0.06 & 0.20 & 0.15 & 0.10 & 0.05 & -0.05 & 1.15 & 0.04 \\
\hline & 20 & 0.12 & 0.05 & 0.21 & 0.13 & 0.09 & 0.05 & -0.05 & 1.16 & 0.03 \\
\hline & 40 & 0.12 & 0.05 & 0.21 & 0.13 & 0.09 & 0.05 & -0.05 & 1.15 & 0.02 \\
\hline \multirow[t]{3}{*}{$(S G D / U S D)_{t}$} & 10 & -0.07 & -0.08 & 0.03 & -0.04 & -0.08 & 0.03 & 0.02 & 0.21 & 0.56 \\
\hline & 20 & -0.12 & -0.10 & 0.03 & -0.07 & -0.09 & 0.05 & 0.03 & 0.15 & 0.53 \\
\hline & 40 & -0.16 & -0.12 & 0.03 & -0.11 & -0.10 & 0.07 & 0.03 & 0.12 & 0.50 \\
\hline \multirow{6}{*}{$\begin{array}{l}\text { To Shocks from } \\
\text { all others }\end{array}$} & & & & Respon & of & & & & & \\
\hline & Horizon & $(E U R$ & $(S E K /$ & $(\mathrm{CHF} /$ & $(D K K /$ & $(G B P)$ & $(C A D)$ & $(N Z D /$ & $(J P Y$ & $(S G D)$ \\
\hline & days) & $/ U S D)_{t}$ & $U S D)_{t}$ & $U S D)_{t}$ & $U S D)_{t}$ & $U S D)_{t}$ & $U S D)_{t}$ & $U S D)_{t}$ & $/ U S D)_{t}$ & $U S D)_{t}$ \\
\hline & 10 & 1.54 & 1.12 & 1.80 & 2.17 & 1.06 & 0.37 & -0.02 & 3.01 & -0.04 \\
\hline & 20 & 1.59 & 1.18 & 1.78 & 2.25 & 1.10 & 0.40 & -0.04 & 3.11 & 0.02 \\
\hline & 40 & 1.68 & 1.23 & 1.78 & 2.30 & 1.15 & 0.38 & -0.05 & 3.20 & 0.13 \\
\hline
\end{tabular}


The generalized impulse responses in both periods provide results summarized in Tables 8 and 9, which are consistent with the findings based on the variance decompositions. Together, they indicate a generally closer intra-regional and interregional linkages, particularly with the European swap markets and between the European swap markets and the rest of the world. Unlike the variance decompositions which separates the variations in one variable into the component shocks to the VAR and provides information about the relative importance of each random innovation in influencing the variables in the VAR, the impulse response functions trace the effects of a shock to one variable on the other variables in the VAR, essentially giving information on both the magnitude and direction of impact of a shock to one variable on another variable. For instance, from the table, it is seen that a positive shock in CHF/USD swap market, which tightens the CHF/USD cross-currency swap, had a low negative impact on EUR/USD cross-currency swap spread (slight widening of the EUR/USD swap spread) before the crisis but had a strongly positive impact on the EUR/USD swap spread as well as the other European cross-currency swap spreads, in the post-crisis period.

Finally, the rolling forecast error variance decompositions are displayed in the graphs in Fig. 4 below. Figure 4 presents the average percentage of forecast error variance decomposition for each cross-currency swap explained by all other crosscurrency swaps at the 40-day horizon. We report below the results for each of the five European cross-currency swaps. Those of the other four cross-currency swaps are presented in Appendix A.

\section{Fig 4: Average percentage of forecast error variance decomposition}
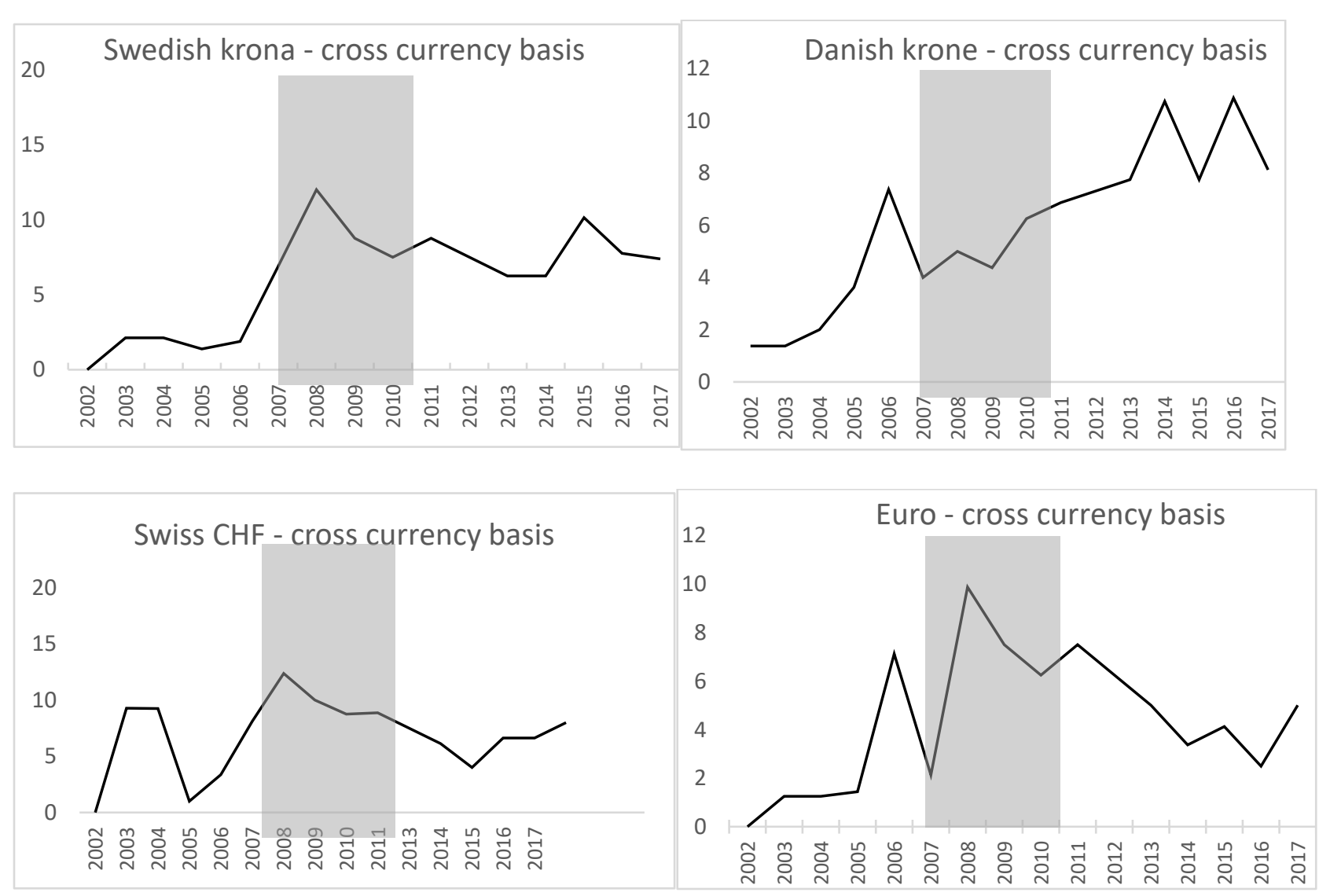


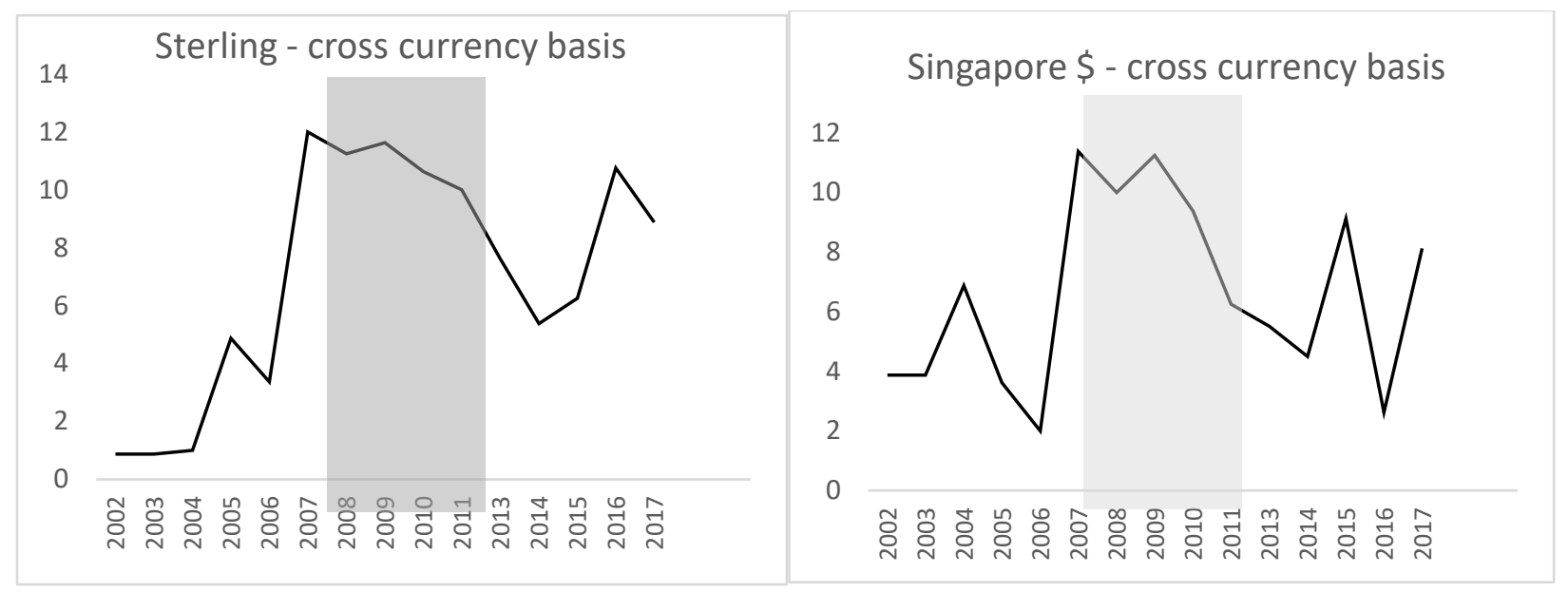

Note: Rolling estimates of forecast error variance decompositions (average of all other swap spreads at the horizon of 40-day, percentage). The shaded area corresponds to the crisis period. The co-integration rank is one. Horizontal axes are estimation end periods of each window. The 9 variables in the models are daily cross-currency basis swap spreads of the 9 currencies, libor based, USD. The 52-week rolling variance decomposition analysis is an additional robustness check on the results for the variance decompositions obtained in the pre-crisis and post-crisis periods. This helps to provide a systematic analysis of robustness of results regarding the possibility of sub-sample instability in periods covering the pre-crisis and post-crisis era.

As can be seen from the graphs in Figure 4, for most of the European cross-currency swaps, the linkages with other swaps are generally stronger in the post-crisis period than in the pre-crisis period. The results are largely similar at the 10- and 20-day horizons (to conserve the space and for ease of presentation, results for these horizons are not shown but are available on request). The higher percentage indicates stronger linkages. Overall, the results indicate that the European cross-currency swap markets became more intra- and inter-regionally linked in the post-crisis period. It can also be observed that the short-run dynamic linkages of the cross-currency swap spreads appear to peak within the neighborhood of the crisis for each swap.

\section{Policy Implications and Benefits of Findings for Investment Management}

With the finding that the long-run co-integration relationships among European and other cross-currency basis swap spreads weakened after the crisis while the short-run dynamic linkages were strengthened, there are several short-and long-run practical implications for investment managers. The results in this paper, though have diverse implications in varied areas of finance, are targeted at investment managers whose investment objectives are not limited to taking positions in assets traded in their respective domestic markets but also include getting exposure to foreign assets. Thus, in more general terms, the main practical investment management implications of our results are most relevant to investment managers with existing positions in foreign markets or with plans to take positions in foreign markets by investing in assets denominated in foreign currencies. The implications are articulated as follows. 
As we have seen, it turns out that the short-run linkages among the cross-currency swap spreads have strengthened in the post-crisis period compared to the pre-crisis period. The strengthened short-run dynamic linkages suggest that in the more near term, events which influence European basis swap spreads, especially euro and swiss basis swap spreads, cause a higher variability in other basis swap spreads. That is, their influence on others in the short run has become stronger and the odds that shocks to these swaps drive variability in other swaps have increased. The implication for investment management is that: if investment managers desire to take positions in assets in a foreign market, and they wish to enter a deal in the cross-currency swap market to secure the required foreign currency whilst minimizing costs or risks, then, more than ever before, they must pay an increased attention to the European swaps, especially the euro and swiss basis swap spreads, before entering the transactions, given the increased short-term links between these basis swap spreads with other basis swap spreads in the post-crisis period. This implication is better illustrated with the example presented below.

\section{5a. Hypothetical Scenarios for Illustrative Purposes}

Suppose two competing Danish investment managers A and B look to invest in an asset which has historically generated impressive risk-adjusted returns. The asset does not trade domestically, but is available in a foreign market, say in the US market, and trades in the USD. To invest in this asset, both investment managers, as a first step, approach the crosscurrency swap market which enables them to enter a currency transaction and raise the required USD to facilitate investment in the asset in exchange for their own currency. For this transaction, timing of entry into the cross-currency market is important. As we will see, entering at appropriate levels enables the investment managers to benefit from the full advantages available in the swap market.

Suppose investment manager A is unaware that the short-term linkages between EUR/USD basis swap spread and other basis swap spreads, particularly Krone/USD basis swap spread, have strengthened post-crisis period. However, investment manager $\mathrm{B}$ has access to the finding that the linkages have strengthened, and that shocks to EUR/USD crosscurrency basis explain significant variability in other basis swaps on impact and for a few days ahead.

Assume the Krone/USD cross-currency basis is minus 50bp. Now suppose some shocks cause the EUR/USD basis to widen. Since investment manager B knows that the EUR/USD basis explains a significant amount of variability in the Krone/USD basis both on impact and in few periods ahead, he quickly approaches the swap market to lock in the current level of basis at minus 50bp as he is aware that because of the increased links, the Krone/USD basis is also likely to widen further in the period ahead as EUR/USD basis has widened. Meanwhile, due to ignorance, investment manager A enters the swap market 20 days later when the Krone/USD cross-currency basis has widened significantly to minus $150 \mathrm{bp}$.

Now, in the swap market, both investment managers A and B each swap 24,000,000 Krone at a spot exchange rate of, say, 6 Krone per dollar, to get 4,000,000 USD each. Assuming a USD libor of 250bp and Krone libor of 350bp, at the 
Krone/USD cross-currency basis of minus 50bp, investment manager B receives (350bp minus 50bp) of 24,000,000 Krone, or 720,000 Krone, for the amount of Krone provided to the swap market and pays 250bp of 4,000,000 USD, or 100,000 USD, for the amount of USD borrowed from the swap market. However, because of the wider cross-currency basis of minus 150bp, investment manager A receives much less, at (350bp minus 150bp) of 24,000,000 Krone, or 480,000 Krone, for the same amount of Krone provided to the swap market but pays the same cost as manager A, i.e. $250 \mathrm{bp}$ of 4,000,000 USD or 100,000 USD, for the dollars borrowed from the swap market.

With the 4,000,000 USD obtained from the swap market, both investment managers invest in the high yielding asset in the foreign market. Let us assume the asset in the foreign market is a one-period bond paying a fixed rate. Suppose that, for that period, it turns out the asset generates a return equal to the dollar libor, i.e. 250bp. In this scenario, investment managers A and B each earn 250bp of 4,000,000 USD, or 100,000 USD, from their investment in the foreign asset. Meanwhile, as noted earlier, it costs both investment managers the same 100,000 dollars to borrow USD in the swap market. This nets out the dollar returns realized from investing in the foreign asset for both investment managers.

However, in the swap market, investment manager A has accumulated an inflow of 720,000 Krone for entering the cross-currency swap market at an appropriate level whereas investment manager B, because of ignorance, earns 33.3\% lower, which equates to 480,000 Krone, for providing the same amount of Krone to the market.

So, overall, the knowledge of increased short-term linkages among the cross-currency swap spreads made the difference in the investment outcomes between both investment managers. Though both investment managers' returns from investing in the foreign asset were netted out by the cost of securing USD in the swap market, yet the cross-currency swap market provided some gains and the investment manager with awareness of the state of the short-run links among basis swap spreads made more gains. This illustrative example shows how knowledge of the state of the short run linkages among cross-currency swap spreads can make a noticeable difference for investment managers as they look to expand their portfolio composition and optimize their portfolio income. The entry level in a cross-currency swap transaction is germane and we argue that a knowledge of the extent to which the basis swap spreads are linked provides an informative platform to gauge an appropriate entry point in the post-crisis period.

However, these links are shown to have weakened in the long-run, so that it becomes less probable for investment managers to position at a level of cross-currency basis swap spreads that offer distinctive advantages further into the future. As we have shown in this paper, the long-run co-integration relationships among European and other crosscurrency basis swap spreads weakened after the crisis. The weaker long-run relationship among the-cross currency basis swap spreads in the post-crisis era has two implications. One, it implies that an investment management strategy which profits from the divergence of basis swap spreads by simultaneously buying one basis swap when it falls below its predivergence level and selling another basis swap when it rises above its pre-divergence level as become less profitable or, in the worst scenario, does not yield a profitable outcome, compared to the pre-crisis period. This is because when the long-run equilibrium relation breaks, causing a divergence or deviations from the long -run path, and an investment 
manager takes a position, the position may take a longer time to unwind, or it may not even be unwound because the investment manager is stuck in the position, due to the decline in the speed required for the long run relationship to be reestablished to enable the fund manager cash out, unwind and take profit. Unlike in the pre-crisis period when this relationship is restored much faster, the post-crisis period is different. In other words, simultaneous positions in European and other swaps takes a longer time to yield profitable outcomes in the post-crisis period compared to the precrisis period and may no longer be profitable. Second, and perhaps more constructive, the weaker long-run relationships among the swaps implies that the benefits of diversification have increased in the post-crisis period compared to the pre-crisis period. For an investment manager with a portfolio of cross-currency swaps, it has become more possible in the post-crisis period, relative to the pre-crisis period, to gain some long-term diversification benefits by expanding the number of cross-currency swaps in the portfolio given the long-run relations among the swaps have weakened, though we note that the strongest long-run diversification for a portfolio of swaps is obtained when there is no long-run relationship among the basis swaps. 


\section{Conclusion}

This study empirically examines how the global and European financial crisis affects the long-run relationship and short-run dynamic linkages among the European and other cross-currency basis swap spreads. In general, the results reveal that the long-run co-integration relationships among the swaps weakened after the crisis while the short-run dynamic linkages were strengthened. Specifically, the after-crisis period is characterized by an increase in the short-run dynamic linkages of the European cross-currency swaps, both regionally and globally, compared to the pre-crisis period. Notably, the influence of EUR/USD cross-currency swap on other European swaps generally increased after the crisis. Moreover, the influence of CHF/USD cross-currency swap became several times more noticeable on all other European swaps after the crisis, but not before the crisis. As a general observation, one of the 'marks' of the crisis is that it has caused these swap markets to become more vulnerable to external shocks from other swap markets, at least in the shortrun. Our findings survive a series of robustness checks such as alternative reordering of variables in our 9-variable VAR system, computation of generalized impulse response functions, and consideration of rolling variance decomposition analysis.

The main takeaway from this paper is that the magnet binding the cross-currency swaps in a long-run relationship has been weakened since the crisis - meaning that the swaps have become quicker to wander and slower to recouple/regroup, implying some mild diversification gains for a portfolio of swaps in the post-crisis period relative to the pre-crisis period. However, the short-run linkages strengthened after the crisis. This means that even if the swaps will eventually wander, it may take a longer time for this wandering to happen in the post-crisis period, compared to the pre-crisis period, because of the strengthening of the short-term ties among the swaps in the post-crisis period. The main result of this article roughly mimics Newton's First Law of Motion - the law of inertia. The reluctance of a body to start moving, and the reluctance of the body to stop moving once it starts moving. In our application, post crisis, there is a reluctance for the cross-currency swaps to wander away as the short-run linkages between them have strengthened. But eventually, when these links break (due perhaps to a system-wide shock), setting the swaps in motion, it would be more difficult for the swaps to return to their state of equilibrium because the speed of convergence, and hence the long run relationship, has weakened. Ultimately, our study suggests that the long-run relations and short-run dynamics among swaps vary in strength and are not fixed over time.

Motivated by findings in this paper, we expect the emergence of more empirical and theoretical studies further examining the links among short and long maturity cross-currency basis swap spreads, possibly beyond what has been presented in this paper. The links established in this paper among major cross-currency swap markets suggest that smaller cross-currency swap markets, especially those in South America and emerging markets which have not been considered in this paper due to data limitations, are possibly linked and influence by major swap markets, i.e. EUR/USD or JPY/USD cross-currency markets. In that sense, it would be interesting to investigate the intra and inter-regional long-run relations and short-run dynamic linkages among these markets. Results from such studies would have 
important implications for funding decisions, arbitrage trading and hedging of cash flows, especially for development institutions that look to engage in development activities in emerging markets but also want to access local currencies at favourable costs in the swap markets and hedge their exposure or positions from the inevitable fluctuations in exchange rates.

Knowing how swaps are linked could improve monetary and macroprudential policies and provide a better insight on how rates in the traditional money market, swap market and even capital market influence the perception of monetary stance and external transmission of monetary policy. Our work presents the first empirical evidence on the long-run relations and short-run dynamic linkages among a broad collection of international cross-currency swap markets in the pre- and post-crisis era. Going forward, it is expected that our findings will stimulate further research in this direction, sooner rather than later. 


\section{References}

Baba, N., Packer F. and Nagano, T. (2008). The spillover of money market turbulence to FX swap and crosscurrency swap markets. BIS quarterly review: international banking and financial market developments, March 2008.

Baran J. and Witzany J. (2017). Analyzing cross currency basis spreads. European Stability Mechanism Working Paper, No. 25.

Du W., Tepper A. and Verdelhan A. (2018). Deviations from covered interest rate parity. The Journal of Finance Vol. LXXIII, No. 3

Pesaran, M. H. and Shin, Y. (1996). Cointegration and speed of convergence to equilibrium. Journal of Econometrics, vol. 71, Issue 1-2, 117-143.

Popper, H. (1993). Long-term covered interest parity: evidence from currency swaps, Journal of International Money and Finance 12: 439-48

Takezawa, N. (1995). Currency Swaps and Long-Term Covered Interest Parity, Economics Letters 49: 181-85.

Tamakoshi, G. and Hamori, S. (2013). Greek sovereign bond index, volatility and structural breaks. Journal of Economics and Finance, vol. 38, Issue 4, 687-697.

White, H. (2001). A heteroskedasticity-consistent covariance matrix and a direct test for heterskedasticity. Econometrica. 48. 817-830. 10.2307/1912934.

Yang, J., Hsiao, C., Qi, L., Wang, Z., (2006). The emerging market crisis and stock market linkages: further evidence. Journal of Applied Econometrics 21, 727-744. 


\section{Appendix A: Average percentage of forecast error variance decomposition, 40 days ahead}
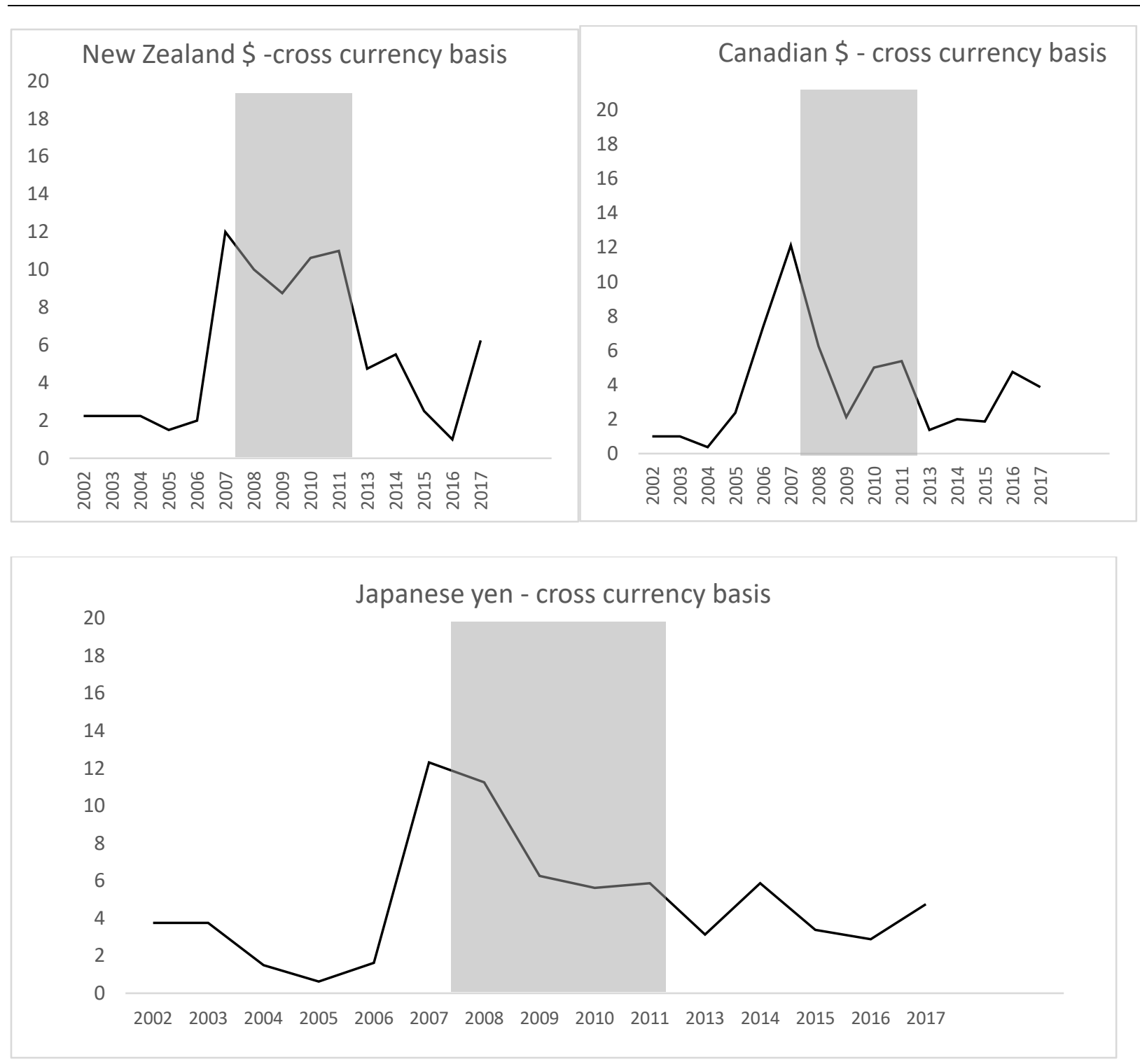

Note: Rolling estimates of forecast error variance decompositions (average of all other swap spreads at the horizon of 40-day, percentage). The shaded area corresponds to the crisis period. The co-integration rank is one. Horizontal axes are estimation end periods of each window. The 9 variables in the models are daily cross-currency basis swap spreads of the 9 currencies, libor based, USD. The 52-week rolling variance decomposition analysis is an additional robustness check on the results for the variance decompositions obtained in the pre-crisis and post-crisis periods. This helps to provide a systematic analysis of robustness of results regarding the possibility of sub-sample instability in periods covering the pre-crisis and post-crisis era. 


\section{Appendix B: Graphs of cross-currency basis swap spreads}

After Crisis

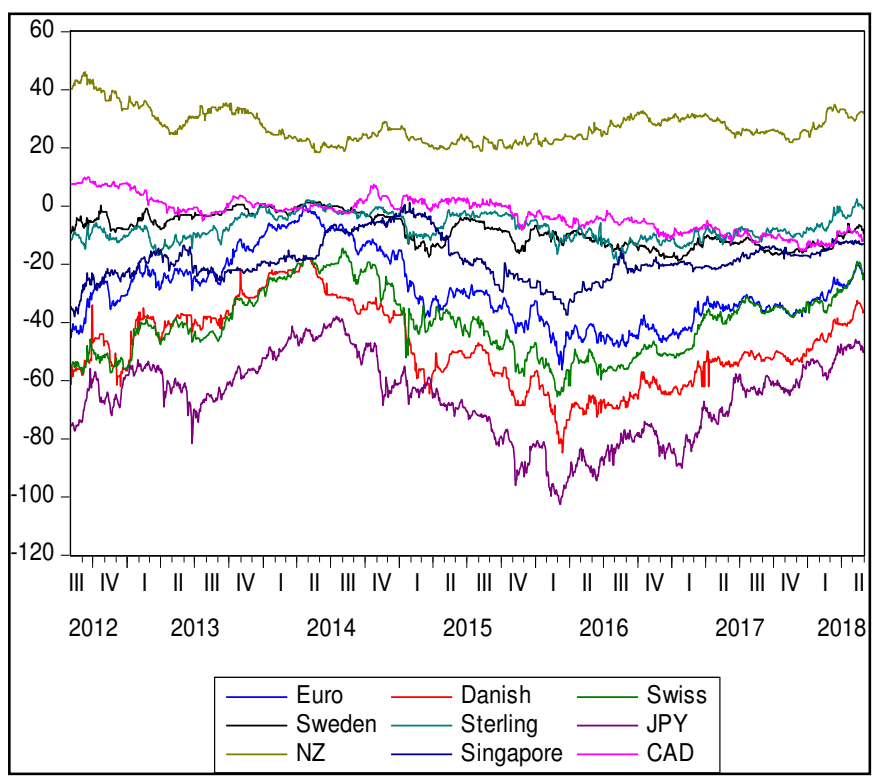

Before Crisis

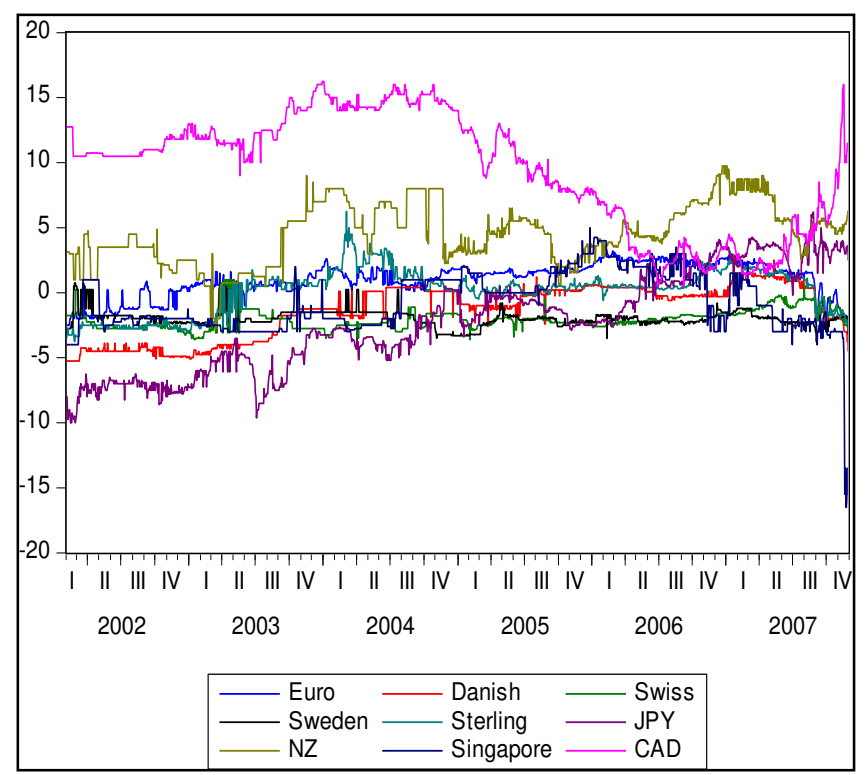

These graphs Note: CAD, CHF, DKK, EUR, GBP, JPY, NZD, SEK and SGD represent Canadian dollar, Swiss franc, Danish krone, Euro, British pound sterling, Japanese yen, New Zealand dollar, Swedish krona and Singaporean dollar respectively while USD represents US dollar. represent plots of 5-year Libor cross-currency basis, measured in basis points, for the different currencies analyzed. 


\section{Appendix B: Covered Interest Rate Parity and Deviations}

\section{i. $\quad$ Covered Interest Rate Parity}

How does it work?

- From Investors Perspective

Investors always want to get the highest possible returns; maximized returns. Investors have two possibilities

1. Invest at Home: Take your dollars, buy a one-year paper (in dollars) and earn the associated dollar libor interest on it (in dollars too). At the end of one-year period, total amount received from the transaction, all in dollars, equals: Principal Invested + Periodic Interest Earned - Transaction Cost Incurred (brokerage fees in the US etc.). Let's call this $T A_{\text {direct }}$, where

$$
T A_{\text {direct }}=P\left(1+r_{u s}-\tau_{d}\right)
$$

2. Invest Abroad: This happens in separate phases. You first go and enter a currency deal at the swap market and get the currency of choice, invest the money in the bond market, cash out of the bond market and finally take the proceeds to the swap market and convert/swap it back to the original currency (US dollars) at the earlier-agreed forward rate. The phases are summarized below

\section{A. In the swap market}

- Take those dollars to the foreign exchange swap market.

- Convert them to, say, euro at the prevailing spot rate, $S$. The euro will be used for investment in bonds in Europe.

- At the swap market, agree, in advance, a reasonable forward exchange rate at which the total amount in euro would be converted (swapped) back to the dollar. You're a US investor, so you want to cash out in the US dollar/bring dollar to the US.

\section{B. In the foreign (euro) bond market}

- Armed with the euro gotten from the swap market, buy a one-year euro paper and earn the associated euro-libor interest on it - in euro.

- After a one-year period, total amount in euro received from the transactions equals: Principal Invested + Periodic Interest Earned - Transaction Cost Incurred (brokerage fees in Europe etc.).

\section{Return to the swap market to cash out}

- As a US investor, it is ideal to cash out in US dollars. So, the euros earned are converted to the US dollars. This takes places once again at the swap market. 
- Thus, at the swap market, the euros earned are swapped into the US dollars. This swap is done at the forward exchange rate $F$ agreed one-year earlier when the investor first approached the swap market to convert dollars to euros in order to invest in the euro bond market.

- The total amount earned/received in euro, from investing in the euro market, is converted to the US dollars at this earlier agreed forward rate, $F$, giving the value of the total amount earned in US dollars. Let's call this $T A_{\text {synthetic }}$, where

$$
T A_{\text {synthetic }}=\frac{P S\left(1+r_{\text {euro }}-\tau_{\text {euro }}\right)}{F}
$$

\section{Covered Interest Rate Parity}

For covered interest rate parity to hold, the investor cannot profit more by investing abroad or investing domestically in the US. In other words, when expressed in the same USD currency, investor makes the same abroad as he would make at home. In other words, $T A_{\text {direct }}=T A_{\text {synthetic }}$.

$$
\left(1+r_{u s}-\tau_{d}\right)=\frac{S\left(1+r_{\text {euro }}-\tau_{\text {euro }}\right)}{F}
$$

In words, total amount received by investing domestically a sum $P$ in the US paper is the same as the total amount received by converting that sum $P$ to the euro, investing the euro proceeds in a euro paper in the euro bond market and swapping/converting the total euro amount earned from the investment to US dollars at the forward rate agreed in advance earlier. This equality, otherwise known as a no arbitrage condition, is the main assumption/building blocks of the covered interest rate parity condition.

\section{ii. Deviations from Covered Interest Parity}

When there are deviations from covered interest rate parity, this implies the covered interest rate parity condition fails to hold and the above equality breaks down. When there are large deviations from covered interest rate parity, the inequality between $T A_{\text {direct }}$ and $T A_{\text {synthetic }}$ becomes larger. It is the deviations from covered interest rate parity condition that imply the existence of a cross-currency basis swap spread. The cross-currency basis swap spread is thus the differential or spread between the total amount realized investing domestically and the total amount realized investing abroad and swapping proceeds to the domestic currency at the agreed forward exchange rate. The literature is rife with the possible cause or driver of these deviations, and that is not the focus of this paper.

Meanwhile, when $T A_{\text {direct }}-T A_{\text {synthetic }}<0$, then it is more profitable investing abroad and swapping proceeds into the domestic currency, than it is investing domestically. Otherwise the converse is true.

\section{- From Borrowers Perspective}

Borrowers always want to pay the least possible cost; minimized costs. Borrowers have two possibilities 
1. Borrow at Home: Issue a paper/bond in the domestic market (in dollars) and pay the associated dollar interest/coupon on it to the investors and lenders. At maturity, pay back the money borrowed. For simplicity purposes, we suppose a one-year paper is issued to borrow a sum $\mathrm{P}$ in the domestic market, where the prevailing domestic interest rate applied is $r_{u s}$. At the one-year maturity, and assuming no default, the borrower pays back, in dollars, Sum Borrowed + Periodic Interest Cost + Transaction Cost Incurred in raising the money. Let's call the total payback $T P_{\text {direct }}$, where

$$
T P_{\text {direct }}=P\left(1+r_{u s}+\tau_{d}\right)
$$

2. Borrow Abroad and Swap to Domestic Currency (Synthetic US Dollar): This is in phases. Issue bonds, for example, in euro, at the prevailing euro interest rate, to borrow $E$ amount of euro in the European bond market, swap the euro proceeds to the required sum $P$ in USD at the spot exchange rate, $S$, i.e. $E / S=P$, where $P$ is now synthetic dollar (i.e. it is obtained by swapping another currency (euro) to $P$ USD). Agreement is made in advance a forward rate $F$ at which the $P$ USD raised will be reconverted or swapped to euro for repayment of the money borrowed in euro. After the one-year period, reconvert the synthetic $P$ USD to euro at the forward rate $F$, giving $P / F$ euro. Pay back the money borrowed in euro, with the required interest rate cost and transaction cost. Total amount paid back to lenders or buyers of the bond or creditors is

$$
T P_{\text {synthetic }}=\frac{E\left(1+r_{\text {euro }}+\tau_{\text {euro }}\right)}{F}=\frac{S P\left(1+r_{\text {euro }}+\tau_{\text {euro }}\right)}{F}
$$

\section{Covered Interest Rate Parity (CIP)}

If CIP holds, then it is not cheaper to borrow outside than it is to borrow at home as the cost associated with borrowing, when expressed in the same currency, is the same. i.e.

$$
\begin{gathered}
T P_{\text {direct }}=T P_{\text {synthetic }} \\
\left(1+r_{u s}+\tau_{d}\right)=\frac{S\left(1+r_{\text {euro }}+\tau_{\text {euro }}\right)}{F}
\end{gathered}
$$

When there are deviations from CIP, then it can be cheaper to borrow synthetic dollars, by issuing in a foreign currency and swapping the proceeds to dollars, than to borrow dollars directly.

\section{Existence of Cross-Currency Basis Swap Spreads and Implications for Borrowing}

When there are deviations from covered interest rate parity, i.e. when the cross-currency basis swap spread is non-zero, then, as said, it is possible to access a foreign currency/borrow a foreign currency in the swap market at a comparatively lower cost. The details of how this works out are presented below. 


\section{Case 1: To borrow synthetic dollar In the Swap Market}

Assume deviations from CIP, i.e. existence of non-zero cross-currency basis swap spreads. Suppose a Yen holder who has $Y$ amount of Yen wishes to access an equivalent amount in USD. Let the spot exchange rate be $S$, then the USD to be borrowed, when expressed in Yen, is equivalent to the amount of Yen $Y$ according to the simple relation, $U S D \times S=Y$.

The Yen holder swaps this $Y$ amount of yen for the equivalent USD, receiving some return on his yen and paying some cost for accessing USD throughout the life of the swap contract. Let the non-zero Yen/USD crosscurrency basis swap spread be $-\delta_{Y e n / U S D}$, where, as it is understood in the market, the basis swap spread is on the non-dollar leg, and the Yen/USD cross-currency basis is negative. Let the yen libor rate be $r_{y e n}$ and let the US dollar libor rate be $r_{U S D}$.

In the swap market, the yen holder receives a return of $r_{y e n}+\left(-\delta_{Y e n / U S D}\right)$ on the $Y$ amount of swapped yen and pays a cost of $r_{U S D}$ on the USD dollars borrowed. Thus, he receives $\left[r_{y e n}-\delta_{Y e n / U S D}\right] \times Y$ and incurs a cost of $r_{U S D} \times U S D$, where the cost is in dollars. Converting the dollar costs at the spot exchange rate, $\mathrm{S}$, yields the cost in yen as $\left(r_{U S D} \times U S D\right) \times S$.

Ignoring transaction costs, the net cost $N C$, in yen and to the yen holder, of accessing/borrowing the dollars in the swap market is given by

$$
N C=\left(r_{U S D} \times U S D\right) \times S-\left[r_{y e n}-\delta_{Y e n / U S D}\right] \times Y
$$

Using the equivalence relation $U S D \times S=Y$, we have

$$
N C=\left[r_{U S D}-r_{y e n}+\delta_{Y e n / U S D}\right] \times Y
$$

and

$$
\frac{\partial N C}{\partial r_{U S D}}=1>0, \quad \frac{\partial N C}{\partial r_{y e n}}=-1<0, \quad \frac{\partial N C}{\partial \delta_{Y e n / U S D}}=1>0
$$

From (3), several deductions are possible. First, the higher the USD libor rate, the higher the net cost incurred by the yen holder to borrow the dollar in the swap market by swapping yen. Second, the higher the yen libor rate, the lower the net yen cost of accessing the USD in the swap market via swapping yen. Last, the wider the Yen/USD cross-currency basis swap spreads, the more expensive it is to access USD in the swap market via swapping the yen. In order words, the tighter or less negative is the Yen/USD cross-currency basis, the lower the net cost of assessing the dollar via swapping the yen in the swap market.

By the end of the transaction in the swap market, both parties get their original currency alongside some return. The original dollar holder gets back USD principal and stream of interests, so he gets USD+ $r_{U S D} \times U S D$, assuming a one-year contract period. The original yen holder also gets back yen principal and a stream of interests/returns. So, he gets $Y+\left[r_{y e n}-\delta_{Y e n / U S D}\right] \times Y$. 


\section{Case 2: To borrow synthetic dollar: by first issuing the yen in the JPY market and then swapping to USD in} the swap market

In the preceding illustration, we have assumed that the synthetic-dollar borrower already has the $Y$ amount of yen. Suppose instead that this is not the case, and that the agent needs to first borrow the yen by issuing yen bond in the Japanese market before approaching the swap market to borrow synthetic dollar as in Case 1.

Suppose the agent issues a Japanese local bond, at a rate $r_{i s s u e}$, to raise the $Y$ amount of yen. He incurs an additional cost $r_{\text {issue }} \times Y$. Net total cost (in yen) to issue (borrow) the $Y$ amount of yen and then use it (as a collateral) to borrow the synthetic dollars in the swap market, is given by

$$
N C=\left[r_{i s s u e}+r_{U S D}-r_{y e n}+\delta_{Y e n / U S D}\right] \times Y
$$

Of course, $\frac{\partial N C}{\partial r_{\text {issue }}}=1>0$, so that a high interest on yen bond raises the total net cost of getting synthetic dollars while a lower cost of issuing yen bond reduces the overall net cost incurred to access synthetic dollars. The low interest rate in Japan for decades made Japanese yen very much attractive as a major funding currency. Because of the low interest, global institutions issue enormous amounts of bonds in yen and swap the proceeds to the USD in the swap market, resulting in a much lower overall net cost of accessing USD.

That said, by the end of the whole transaction,

1. The lenders in JPY bond market get back their principal plus interest $Y+r_{\text {issue }} \times Y$

2. The lender of USD in the swap market gets $U S D+r_{U S D} \times U S D$

3. The borrower, who first issued $Y$ yen in the JPY bond market and swapped to USD, receives $\left(r_{y e n}-\delta_{Y e n / U S D}\right) \times Y$ in the swap market. This issuer does not own the principal $Y$, and thus does not get it at the end of the transaction. The original principal, gotten by issuing bond, is returned to the Japanese lenders/bond holders at maturity. If $\left(r_{y e n}-\delta_{Y e n / U S D}\right) \times Y>0$, then the borrower has in fact made some arbitrage profit! which helps lessen the overall net cost of borrowing. If, however, $\left(r_{y e n}-\delta_{Y e n / U S D}\right) \times Y<0$, then there is no advantage of reduced borrowing cost in the transaction. Everything is a cost, outflow, to the borrower; there is no profitable inflow to help lessen entire borrowing cost. 
